\title{
Experimental therapeutic approaches to peripheral nerve tumors
}

\author{
Jonathan Riley, B.S.E., ${ }^{1}$ Alejandro Spiotta, M.D., ${ }^{2}$ AND Nicholas Boulis, M.D. ${ }^{1}$ \\ ${ }^{1}$ Department of Neurosciences and the Center for Neurological Restoration and ${ }^{2}$ Department \\ of Neurosurgery, Cleveland Clinic Foundation, Cleveland, Ohio
}

\begin{abstract}
$\checkmark$ Discovery that the Schwann cell is the primary cell type responsible for both the neurofibroma as well as the schwannoma has proven to represent a crucial milestone in understanding the pathogenesis of peripheral nerve tumor development. This information and related findings have served as a nidus for research aimed at more fully characterizing this family of conditions. Recent discoveries in the laboratory have clarified an understanding of the molecular mechanisms underlying the pathogenesis of benign peripheral nerve tumors. Similarly, the mechanisms whereby idiopathic and syndromic (NF1- and NF2associated) nerve sheath tumors progress to malignancy are being elucidated. This detailed understanding of the molecular pathogenesis of peripheral nerve tumors provides the information necessary to create a new generation of therapies tailored specifically to the prevention, cessation, or reversal of pathological conditions at the fundamental level of dysfunction. The authors review the data that have helped to elucidate the molecular pathogenesis of this category of conditions, explore the current progress toward exploitation of these findings, and discuss potential therapeutic avenues for future research.
\end{abstract}

KeY WORDS - experimental therapy - malignancy - neurofibroma - schwannoma • tumor

$\mathrm{P}$

ERIPHERAL nerve tumors comprise both benign and malignant variants. Benign tumors are predominantly either schwannomas or neurofibromas. The for-

\footnotetext{
Abbreviations used in this paper: ATP $=$ adenosine 5' triphosphate; bFGF = basic fibroblast growth factor; EGF = epidermal growth factor; ER = ezrin-radixin-moesin; FGF = fibroblast growth factor; FTI = farnesyl transferase inhibitor; GAP = GTPase associated protein; GDP = guanosine diphosphate; GEF = guanine nucleotide exchange factor; GRD = GAP-related domain; GTP = guanosine triphosphate; HMG-CoA = 3-hydroxy-3-methylglutaryl coenzyme A; HSV = herpes simplex virus; $\mathrm{LOH}=$ loss of heterozygosity; MAPK = mitogen-activated protein kinase; $\mathrm{MK}=$ midkine; MPNST = malignant peripheral nerve sheath tumor; $\mathrm{mTOR}=$ mammalian target of rapamycin; $\mathrm{NF}=$ neurofibromatosis; NF1 = NF Type 1; NF2 = NF Type 2; NIH = National Institutes of Health; NGF = nerve growth factor; PDGF = platelet-derived growth factor; PI3K = phosphoinositide 3-kinase; Raf = Ras activated factor; $\mathrm{SCF}=$ stem cell factor; TGF = transforming growth factor; VCAM = vascular cell adhesion molecule; VEGF = vascular endothelial growth factor; VEGFR-2 = VEGF receptor 2.
}

mer represent approximately $5 \%$ of all benign tumors of the soft tissue. Absence of the NF2 gene is required for tumor development. The gene is located on chromosome 22 and is variably called schwannomin or merlin. When not present in isolation, the tumors are associated with either NF2 or schwannomatosis, indicating the presence of a germline mutation and subsequent $\mathrm{LOH}$. Tumors have been isolated intracranially and extracranially, in both major peripheral nerve complexes and in small distal branches, and in somatic as well as autonomic nerves. Because they arise endoneurally, they are encapsulated by the outer layers of the nerve sheath, the perineurium and fibrous epineurium. Neurofibromas may be localized in up to $90 \%$ of cases and are usually solitary but are most commonly associated with the phacomatosis, NF1, when diffuse. ${ }^{142}$ This autosomal dominant condition is associated with a variety of occult findings related to inactivation of the NF1 tumor suppressor gene found on chromosome 17. Clinically, the conditions are stratified into localized, diffuse, and plexiform variants. It is particularly from this 
last category that MPNSTs arise. Despite a low overall incidence of NF1 in the general population, over half of the patients with MPNSTs have NF1..$^{56}$ The results of a recent study demonstrated a 5-year postdiagnosis survival of approximately $52 \%$ in patients with MPNSTs. ${ }^{160}$

Current treatment strategies for peripheral nerve tumors include observation, incisional biopsy, and surgical or nonoperative management through the use of radio- or chemotherapy. ${ }^{56}$ Benign idiopathic schwannomas and neurofibromas are unlikely to become malignant, so in the presence of advanced age, minimal symptomatology, and little evidence of progression on imaging studies, it is appropriate to consider conservative therapies. At the opposite end of the spectrum, malignant peripheral nerve tumors are of only intermediate chemosensitivity, are often associated with the presence of clinical symptoms such as pain at rest, display a high rate of progression on imaging studies, and are associated with a high mortality rate. Therefore, surgical attempts to fully resect the tumor mass, when in the presence of a systemic condition (for example, NF1), are required. Unfortunately, despite the advent of improvements in intraoperative microsurgical technique, resection is not a curative approach for malignant peripheral nerve tumors; these tumors continue to pose a significant challenge to practicing physicians. The best results are currently achieved through a close collaboration of allied professionals in a multidisciplinary team to achieve a resection with adequate margins. Standard therapeutic principles are covered in greater depth elsewhere in this issue. Herein, we review the data that has helped to elucidate the molecular pathogenesis of this category of conditions, explore the current progress toward exploitation of these findings, and discuss potential therapeutic avenues for future research.

\section{Molecular Pathogenesis}

The discovery that the Schwann cell is the primary cell type responsible for both the neurofibroma as well as the schwannoma has proven to represent a crucial milestone in understanding the pathogenesis of peripheral nerve tumor development. This information and related findings have served as a nidus for research aimed at characterizing this family of conditions. To date, research efforts have delineated unique gene mutations responsible for each tumor type, elements of the contributory molecular pathways, factors that contribute to malignant progression, and modifying effects of known neurogenetic conditions and mutations on the clinically observed disease course. The following paragraphs focus on recent findings that have clarified the complex molecular interplay responsible for tumor development, specifically discussing neurofibroma, schwannoma, and the elements important for progression to malignancy. The current discussion excludes secondary tumors, hemangiomas arising from capillaries, and ganglion tumors arising from the sympathetic nervous system (for example, ganglioneuromas and ganglioneuroblastomas). Figure 1A summarizes the present knowledge of the distinct but related molecular mechanisms responsible for tumorigenesis, while Fig. 1B emphasizes the critical role of neurofibromin and merlin in the dysregulation of intracellular pathways respectively responsible for neurofibroma and schwannoma development.

\section{Neurofibroma Development}

The Role of Neurofibromin. The NF1 locus, present at $17 \mathrm{q} 11.2$, has an overall genomic size of approximately $350 \mathrm{~kb}$ spread across 60 exons. It was initially recognized and isolated as the gene responsible for development of $\mathrm{NF} 1$, an autosomal neurogenetic condition responsible for a wide range of cutaneous and systemic sequelae. In addition to the primary transcript, the NFI gene locus contains an additional three genes within the span of exon 27 and a pseudogene within intron 37. ${ }^{16,112}$ To date, four different transcripts have been identified, without evidence of posttranslational processing. The product of interest, neurofibromin, is a 2818-amino-acid protein that is generated in a wide variety of tissues but has elevated expression in the nervous system. ${ }^{27,152}$ Specifically, it is localized to the cytoplasm and has been colocalized with microtubules. ${ }^{46}$ Expression is present during embryological development and reaches adult levels after 1 week of postnatal life. ${ }^{48-50}$ Physiologically, neurofibromin has been shown to play an important upstream role as a negative regulator of the mitogen signal transduction cascade mediated by $\mathrm{p} 21-$ Ras.

Multiple classes of extracellular mitogens or growth factors activate transmembrane receptor tyrosine kinase signaling proteins that are phosphorylated on intracytoplasmic domains and, in turn, activate intracellular GEF proteins. Activated GEF proteins result in exchange of GDP for GTP on the membrane-associated Ras protein. The now-activated Ras-GTP is capable of interacting with effectors of unique but related downstream signaling cascades that promote the broad cellular end points of proliferation and apoptosis inhibition. Specifically, activated Ras-GTP is known to act through two predominant signaling pathways: Ras/PI3K and the Ras/Raf (Ras-activated factor)/MAPK pathway. The Ras/PI3K pathway achieves antiapoptotic effects divergently through $\mathrm{NF}_{\mathrm{K}} \mathrm{B}$ and through Akt-mediated signaling. The former directly alters gene transcription through nuclear transduction while the latter helps to stabilize mediators of the cytoplasmic apoptotic response. An additional Ras/PI3Kmediated pathway downstream of Akt, mTOR, has recently been demonstrated to be constitutively upregulated in the absence of neurofibromin. ${ }^{25,62}$ This pathway, known widely to play a role in malignant cell growth, is exquisitively sensitive to rapamycin-related agents. ${ }^{23}$ Further, these initial studies have indicated that tumorderived cell lines are responsive to rapamycin. ${ }^{62}$ Cell proliferation is promoted by Raf kinase activation and nuclear transduction through activation of Mek, Erk1, and Erk2 MAPK isoforms. Neurofibromin acts as a physiological counterbalance, inhibiting these downstream effectors through inhibition of the activated Ras protein following clearance of extracellular signaling molecules. ${ }^{19}$ Activation of intrinsic Ras GTPase functionality, by a GTPase-related domain present on neurofibromin, results in cleavage of GTP to GDP and subsequent inactivation of the Ras protein. Therefore, neurofibromin acts 


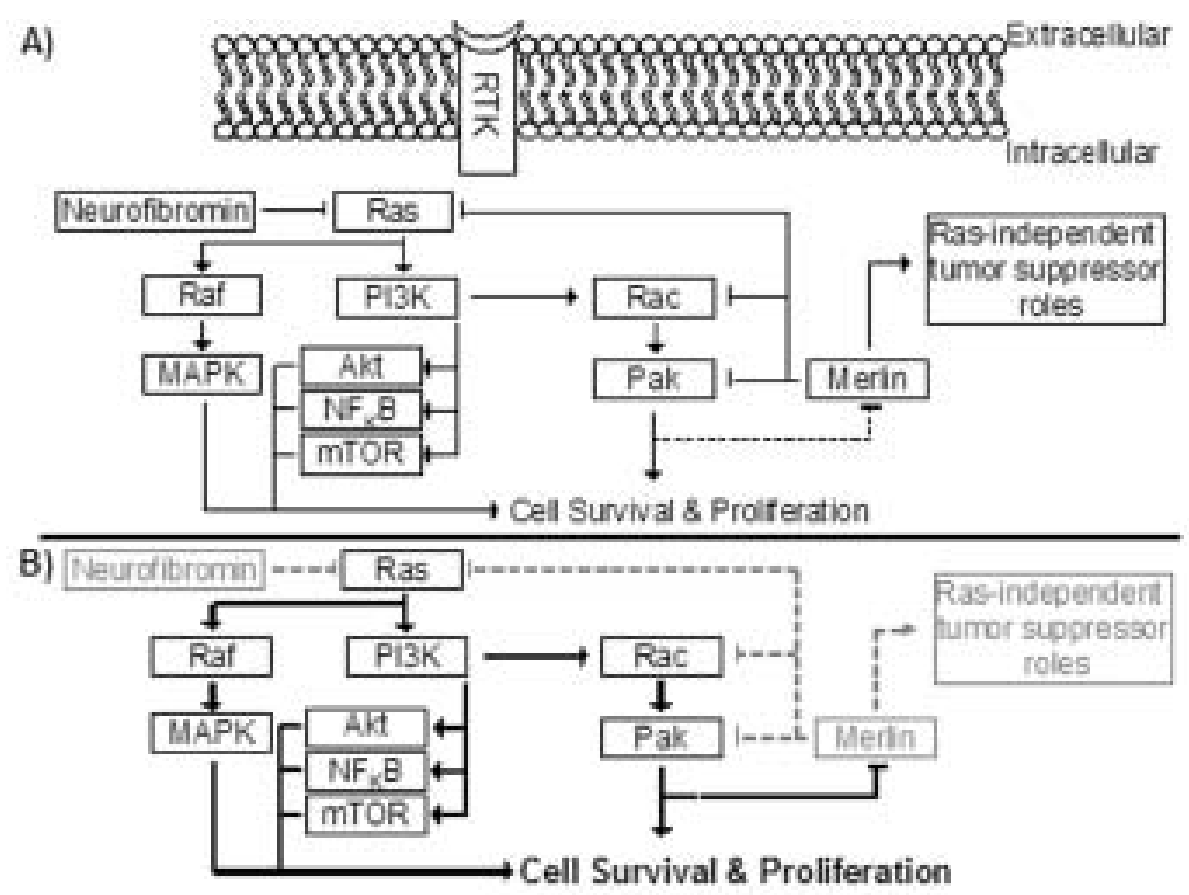

FIG. 1. Schematic illustration of the molecular mechanisms of tumorigenesis: effects of loss of neurofibromin and merlin and initiation of tumorigenesis. A: Both Ras-dependent and Ras-independent signaling cascades are depicted as regulating the broad downstream end points of cellular survival and proliferation through multiple parallel intracellular pathways. Further, the role of neurofibromin and merlin as physiological counterbalances depressing the activity of these pathways is shown. B: Loss of functional neurofibromin and merlin, respectively, are known to be central to cellular transformation to the neurofibroma and schwannoma. Loss of neurofibromin function results in constitutive activation of Ras-mediated signaling while inactivation of merlin contributes to elevated signaling within Ras-dependent and Rasindependent pathways. RTK = receptor tyrosine kinase; TRBP $=$ transactivation-responsive RNA-binding protein.

as a negative regulator of separate proliferative and cell survival pathways through upstream inhibition of Rasmediated signaling.

The central role played by Ras in the balance of cell growth and survival underscores the importance of disturbances in the Ras pathway. Its dysregulation has been implicated as a contributor to cancer development. ${ }^{59}$ More specifically, constitutively upregulated Ras activity, as in the absence of neurofibromin, has been demonstrated to contribute to a range of human cancers. ${ }^{158}$ Homozygous loss of neurofibromin, a condition promoted in the context of the inherited condition NF1, represents the central requirement for tumor development. However, definitive demonstration has required construction of elegant experiments, in part because the neurofibroma tumor microenvironment is heterogeneous, containing Schwann cells, perineural cells, endothelial cells, mast cells, and fibroblasts. ${ }^{134}$ Because the NF1 gene is required for embryological development, the potential for use of an $N F 1$ knockout animal model is abrogated. Further, heterozygosity does not predispose mice to tumor development. ${ }^{13,58}$ Le and Parada ${ }^{75}$ have addressed this issue by hypothesizing that the lack of correlation with the human condition may result from a smaller neural crest compartment and shorter gestation time in the mouse model. Therefore, use of a conditional knockout in an otherwise $\mathrm{NF}^{+/-}$animal model has been necessary to create Schwann cells lacking both copies of neurofibromin with consequent tumor development. Specifically, the Cre/lox system is employed; Cre is a recombinase that recognizes the short loxP sequences. Thus, the induction of Cre expression in Schwann cells that contain a single copy of neurofibromin flanked by loxP sites results in the removal of the intervening neurofibromin gene and the recombination of the flanking ends. This approach creates an experimental tool that allows conditional suppression of desired genes and has been used to demonstrate that the presence of $\mathrm{NFI}^{-1-}$ Schwann cells is sufficient to promote schwannoma formation in an otherwise heterozygous animal. ${ }^{175}$ This finding has been corroborated more recently by implantation of NF1-deficient Schwann cells into the nerve of an animal model heterozygous for NF1. ${ }^{174}$ Further, the tumorigenic potential is recapitulated when heterozygosity is limited to the local microenvironment, providing evidence for complex feedback mechanisms within this niche. ${ }^{175}$ Both the need for a heterozygous microenvironment and the requirement for neurofibromin during embryological development provide indications for the role of an $\mathrm{LOH}$ event, supporting the role of the two-hit hypothesis in explaining this pathogenic process.

Mechanisms for Tumor Development. Because homozygous loss of functional protein is required for tumor development, it may be expected that a germline mutation precedes a second somatic event in the majority of cases. The autosomal dominant disorder NF1 represents the occur- 
rence of such a germline mutation. In the case of isolated neurofibromas, the first mutation probably occurs during the late embryonic period or during early fetal development. The second event, in all cases a somatic mutation, may or may not result in $\mathrm{LOH}$ but does result in loss of functional protein. A wide range of mutation types have been observed to occur at the NFI locus. In particular, nondisjunction, somatic recombination, and large intragenic deletions may result in LOH. However, loss of protein function may also occur due to the presence of mutations in the intron sequences, altering peptide splicing; the promoter regions controlling expression; or in sequences that repress expression through alteration of methylation patterns. ${ }^{52,138}$ It is important to point out that phenotypegenotype correlation between specific mutations and the clinical course has not been noted. Moreover, no specific predilection for any particular mutation has been noted, with only $7 \%$ of mutations having been observed more than once. ${ }^{156}$ The lack of phenotype-genotype correlation is probably attributable to both the temporal and anatomical heterogeneity of the mutation or "hit" to the second $N F 1$ allele as well as to the lack of a conserved mutational event at a particular hot spot within the NF1 locus. Additionally, it could represent the presence of a "third hit" to a modifier of the pathogenic process. ${ }^{162}$ Modifiers could include proteins that directly or indirectly interact with Ras or alternatively proteins that contribute to tumorigenesis through modification of the local microenvironment.

Contributions of the Local Microenvironment. A large quantity of data implicates the $\mathrm{NF}^{-1-}$ Schwann cell as the initiator of a complex feedback mechanism occurring within the local microenvironment of tumor development. Specifically, a reduction in the presence of neurofibromin is thought to alter the balance of reciprocal feedback mechanisms that normally exist between the cells that constitute the local microenvironment of the peripheral nerve. The initial data generated by Zhu and colleagues, ${ }^{174}$ demonstrating neurofibroma development with the use of a Cre/lox conditional expression system, showed mast cell infiltration only when this cell type was heterozygous at the NF1 locus. Further, the mast cell infiltrate preceded tumor development. The results of tissue culture studies have subsequently confirmed a reciprocal feedback mechanism that is established between the homozygous null $\left(N F 1^{--}\right)$Schwann cell and the heterozygous $\left(\mathrm{NFI}^{++^{-}}\right)$mast cell in the tumor microenvironment. One result of constitutive p21-Ras activation is the increased secretion of the SCF, also known as kit ligand. ${ }^{169}$ Additionally, the authors demonstrated that the NF1 heterozygotic mast cell is both hypermotile and hyperproliferative in the presence of SCF. An increased ability to migrate to the tumor microenvironment requires binding of the mast cell $\alpha_{4} \beta_{1^{-}}$ integrin to the endothelial-derived VCAM-1 cell surface protein. More recently, the authors have demonstrated that the attracted mast cells secrete TGF $\beta$ when heterozygous for NF1 and in the presence of elevated SCF concentrations. ${ }^{168}$ In this study, TGF $\beta$ was demonstrated to act as a profibrotic agent when interacting with heterozygous fibroblasts present in the tumor microenvironment. Additionally, migrated mast cells are known to secrete NGF and VEGF, known stimulants of Schwann cell sur- vival, proliferation, and migration as well as of increased neovascularization. ${ }^{45,143}$ The NF1 heterozygosity of endothelial cells has also been implicated as a contributor to neurofibroma neoangiogenesis. Wu et al. ${ }^{163}$ have recently demonstrated that $\mathrm{NFI}^{+/-}$endothelial cells undergo increased neovascularization when exposed to hypoxia and the angiogenic factor bFGF, as compared to wildtype littermates in a mouse model. Separately, Munchoff et al. ${ }^{107}$ have provided mouse in vitro and in vivo data corroborating these findings and implicating a Ras-dependent pathway, verified in tissue from a patient with NF1, in the process of neoangiogenesis. A wide variety of additional stimulatory autocrine and paracrine growth factors have been implicated as contributors to the tumor-promoting environment. Examples of such Schwann cell mitogens include: hepatocyte growth factor, bFGF, insulin growth factor-1, and MK ${ }^{45}$ Further, Schwann cells upregulate secretion of FGF-2, PDGF, and MK when they lack a functioning neurofibromin gene. ${ }^{45,95}$

In context, the data presented above indicate that a homozygous null $\mathrm{NF}^{-1-}$ Schwann cell is required as the nidus for tumor development. The formation of a neurofibroma is dependent upon the loss of expression of both functional copies of neurofibromin, through a minimum of two critical mutational events and a loss of neurofibromin expression within the already susceptible Schwann cell. In tandem, heterozygosity of the local microenvironment appears to carry an increased susceptibility to tumor transformation. The intracellular imbalance of the Ras-dependent pathways within the Schwann cell results in elevated secretion of growth factors that act in an autocrine and paracrine fashion, additionally promoting release of diffusible chemotactic agents such as SCF. Migration of $N F 1^{+/}$mast cells to the local microenvironment augments the imbalance by promoting fibrosis, neoangiogenesis, and Schwann cell mitogenesis. Finally, other contributors may simultaneously facilitate the transformation cascade through release of additional putative growth factors.

\section{Schwannoma Development}

\section{The Role of Merlin}

The NF2 gene locus is at $22 \mathrm{q} 12.2$ and the gene encodes a protein variably known as merlin or schwannomin. For the sake of clarity, we will refer to this protein as merlin in this review. Like neurofibromin, merlin is required for embryological development. ${ }^{1,50}$ Deficiency of this protein, when localized to the Schwann cell, appears to be both necessary and sufficient to cause cellular transformation and schwannoma development. Heterozygosity at this locus predisposes individuals to development of NF2, an autosomal dominant condition predisposing afflicted individuals to the development of central nervous system (glioma), peripheral nervous system (schwannoma), and other tumors (for example, malignant mesothelioma). This protein represents a novel type of tumor suppressor gene the function of which is incompletely understood but which has been shown to hold significant homology to the 4.1 superfamily of cytoskeleton-associated proteins, specifically the ERM proteins. ${ }^{122}$ A primary known function of ERM proteins is found in linkage of transmem- 
brane proteins to cytoskeletal actin filaments through the presence of a specific actin-binding domain. In line with this role, this family of proteins is thought to contribute to the processes of cell migration, endocytosis, and transmembrane signaling through alteration of the cytoskeletal apparatus. ${ }^{146}$ However, the ERM proteins are also known to achieve proliferative effects through Ras-mediated signaling, opposite to the tumor suppressor role attributed to merlin. ${ }^{18,105}$ Merlin is known to be present in two primary splice variant isoforms encoding peptides of 595 and 590 amino acids, respectively. The 595-amino acid version is capable of forming intramolecular bonds between the amino and carboxyl termini, in a manner inversely dependent upon phosphorylation status. ${ }^{127}$ Dephosphorylation promotes circularization and catalytic activation, whereas phosphorylation inhibits merlin activity. Neither isoform has an actin-binding domain, but the 590-amino acid variant is capable of interacting with $\beta$ II-spectrin, an adapter protein that mediates merlin binding to actin. ${ }^{136}$ The 595-amino acid variant has been posited to exert multiple effects that combine to oppose cellular proliferation and oncogenesis.

Supporting the tumor suppressor role of merlin, the results of in vitro studies have demonstrated that reexpression of merlin in $\mathrm{NF}^{-/-}$cells is capable of arresting the cell cycle at $\mathrm{G}_{0} / \mathrm{G}_{1}{ }^{135}$ This finding is corroborated by other findings indicating that merlin is able to suppress the expression of a critical mediator of the cell cycle, cyclin D1, at least in part through inhibition of Pak-dependent signaling. ${ }^{165}$ Nevertheless, the direct effects of merlin appear to be more proximal, affecting Ras- ${ }^{63}$ and Rac- ${ }^{137}$ mediated signaling pathways, albeit in a fashion that is mechanistically distinct from the action of neurofibromin. The results of in vitro studies have demonstrated that merlin overexpression is capable of inhibiting cell proliferation and anchorage-independent growth mediated by the Ras protein. ${ }^{90,150}$ Further, the membrane-ruffling phenotype of schwannoma cells, a cytological marker of tumorigenic transformation, can be reversed when the Rac isoform Rac1 is inhibited ${ }^{117}$ or when merlin expression is restored. ${ }^{8}$ Morrison et al. have demonstrated, however, that merlin is capable of simultaneously inhibiting both Ras- and Rac-mediated signaling. ${ }^{105}$ Specifically, merlin inhibits activation of Rac and Ras by preventing exchange of GDP for GTP. The authors postulated that inhibition occurred through one of three mechanisms: sequestration of a GDP dissociation inhibitor, inhibition of the catalytic or associative functions of GEF with Ras and Rac, or activation of Ras and Rac GAP activity. The former two options are empirically supported as merlin has been demonstrated to associate with RhoGDI ${ }^{91}$ and Ral-GDS, ${ }^{130}$ a GDP dissociation inhibitor and a GEF protein that act downstream of Ras and Rac, respectively. Interplay between Ras- and Rac-mediated signaling underscores the importance of merlin function at the levels of Ras and Rac. The Ras/Raf-mediated activation of downstream Mek kinases requires prior phosphorylation by $\mathrm{Rac}^{22}$ which may be activated by either Ras-dependent or Rasindependent mechanisms. Inhibition of Rac/Pak signaling has also been demonstrated through merlin-mediated inactivation of PI3K. ${ }^{128}$ Merlin, which has also recently been shown to be stabilized by the presence of an adapter protein, NGB,${ }^{76}$ is inactivated through $\mathrm{Rac} / \mathrm{Pak}$-mediated signaling by phosphorylation. ${ }^{22}$ In contrast, activation through dephosphorylation is at least in part achieved through the action of MYPT-1-PP1- $\delta$, a myosin phosphatase. ${ }^{61}$ Myosin phosphatase activity is stimulated in part through CD44 transmembrane protein activation, providing a mechanism by which cell-cell contact may achieve growth inhibition. ${ }^{104}$ These findings strongly support a tumor suppressor role for merlin through interaction with Rac- and Ras-mediated signaling in mutually inhibitory roles; however, additional data indicate that this protein may serve other roles in preventing cellular transformation.

In parallel with the wealth of data that implicate merlin as the culpable agent responsible for cellular transformation mediated by Ras- and Rac-dependent pathways, alternative findings support the contribution of less canonical pathways. Merlin tumor suppressor activity has recently been associated with mitogen cell surface signaling receptor regulation in conjunction with another protein, Expanded. ${ }^{94}$ In tandem, these proteins have been shown to contribute to the Hippo signaling pathway, achieving additional regulatory effects on cellular proliferation..$^{51}$ Deficiency of merlin has also been demonstrated to contribute to destabilization of intercellular cadherin-containing junctions. ${ }^{74}$ Additionally, merlin has been shown to interact with and inhibit a transactivation-responsive RNA-binding protein, thereby achieving a regulatory effect on cellular proliferation. ${ }^{78,79}$ Although the concerted physiological mechanisms and pathways that enmesh merlin-related signaling have yet to be fully elucidated, a considerable quantity of data implicates significant Rasand Rac-dependent and independent contributions that may provide multiple, varied targets amenable to therapeutic intervention. A summary of the potential tumor suppressor roles of merlin is provided in Table 1.

Mechanisms for Tumor Development. Cellular transformation to schwannoma requires homozygous loss at the causative NF2 gene locus. However, in contrast to the situation regarding NF1 and neurofibroma development, an $\mathrm{NF}^{-/-}$genotype alone appears to be both necessary and sufficient to precipitate schwannoma development. As in neurofibroma transformation, $\mathrm{LOH}$ represents the predominant mechanism responsible for tumor development. However, mutations in nonexpressing genomic regions affecting expression levels have also been observed, specifically with regard to hypermethylation. ${ }^{44,68}$ The results

TABLE 1

Putative Merlin tumor suppressor roles

\begin{tabular}{ll}
\hline \hline \multicolumn{1}{c}{ Factor } & \multicolumn{1}{c}{ Specific Role } \\
\hline Ras & exchange of GDP for GTP \\
Rac & exchange of GDP for GTP \\
PI3K & inactivation of PIKE-L, a PI3K activator \\
Hippo & $\begin{array}{l}\text { growth arrest in Hippo tumor suppresor } \\
\text { pathway in conjunction w/ related protein, } \\
\text { "Expanded" }\end{array}$ \\
TRBP & inactivation of oncogenic transcription factor \\
intercellular junctions & maintenance of cell-cell contact \\
\hline
\end{tabular}


of current studies do not support a critical contribution of the local microenvironment to oncogenesis. Early attempts to generate an $\mathrm{NF}^{-1-}$ mouse model failed due to the requirement of the merlin protein product for embryonic development. ${ }^{98}$ Similar studies examining a heterozygous genotype display a significantly more severe phenotype than is observed in humans, with widespread tumor involvement and considerable progression to malignancy. However, Cre-lox-mediated conditional expression small animal studies, similar to those described above, have largely recapitulated the human disease phenotype, with notable Schwann cell hyperplasia and schwannoma development. ${ }^{43}$

\section{Progression Pathways-Development of Malignancy}

The previous discussion has centered on mutations of the known genes responsible for development of neurofibromas and schwannomas, both when idiopathic and when in the context of the systemic neurogenetic conditions NF1 and NF2. Between one half and two thirds of malignancies related to these conditions occur in patients with NF1, ${ }^{56,72}$ whereas schwannomas have been documented to undergo malignant progression only rarely. ${ }^{161}$ In patients with NF1, malignancies most commonly arise from plexiform neurofibroma variants. Approximately 30 to $40 \%$ of patients with NF1 manifest plexiform tumors in the major nerve trunks, and approximately $10 \%$ of these tumors will undergo progression to malignancy. ${ }^{37} \mathrm{Al}-$ though MPNSTs only occur in a minority of patients with $\mathrm{NF} 1$ and a considerably smaller number of individuals in the general population $(.001 \%),{ }^{32}$ malignant progression represents a warranted cause for concern given the expected prognosis with current therapies. The connection between NF1 and malignancy is of prognostic significance since NF1-related MPNSTs are diagnosed at a younger age (median 26 compared with 62 years of age) and are associated with a lower 5-yr survival rate compared with those occurring sporadically ( $21 \%$ compared with 42\%). ${ }^{36}$ These statistics underscore both the inadequacy of current therapeutic strategies for MPNSTs, which are incapable of achieving a cure, and the need for a more detailed understanding of the molecular mechanisms that support malignant progression.

Difficulty in isolating a consistent molecular mechanism for malignant progression appears to be related to the multilayered heterogeneity found through analysis of both tumor samples and isolated tumor cell lines. In a series of 30 patients with MPNSTs and NF1, NF1 mutations were detected in 27 patients, but neither an association between the mutation type and clinical severity nor a conserved NF1 mutational event was discovered. ${ }^{154}$ Further, the authors were unable to corroborate previous finding of a large intragenic $1.5-\mathrm{Mb}$ deletion as a prognostic contributor. ${ }^{26}$ Nevertheless, results from animal models suggest a role for both the NFI and TP53 genes, in tandem. Mice engineered as compound heterozygotes of both genes were found to recapitulate malignant peripheral nerve tumor development found in humans, with observed loss of both wildtype alleles and full penetrance, ${ }^{20,155}$ but the results of further investigations have indicated that there may be fundamental differences, regarding the roles of NF1 and TP53, between sporadic and NF1-associated malignancies. Bir- indelli and colleagues ${ }^{12}$ noted a significantly higher loss of TP53 heterozygosity in association with NF1. Others have failed to corroborate the finding of an elevated TP53 mutation rate in afflicted patients with $\mathrm{NF} 1,{ }^{70,89}$ while increased nuclear accumulation of the p53 protein has also been implicated. ${ }^{67,97}$ Equipoise exists within the current literature regarding the role of the $\mathrm{p} 53$ protein in malignant progression. Nevertheless, several additional cell cycle regulators have been implicated as potential contributors to the process of malignant progression.

A comparison of microarray data from eight MPNSTderived cell lines and seven normal Schwann cell lines supports a heterogeneous range of expression for multiple cell cycle proteins-including: p16INK4A, p53, p14Arf, and $\mathrm{pRb}$ - serving tumor suppressor roles. ${ }^{101}$ The authors also noted consistent expression of the EGF receptor and S100ß, with concomitant downregulation of Schwann cell differentiation markers and upregulation of neural crest stem cell markers, Sox9 and Twistl. In the context of the same study, data from 45 MPNSTs indicated the presence of a 159 gene "expression signature" sequences unique to the MPNSTs. In the subset of five patients who had NF1, the authors demonstrated loss of p16INK4A (also called $C D K N 2 A$ ). In partial corroboration, Birindelli et al. ${ }^{12}$ noted depression of p16INK4A independent of NF1 status. Miller et al. ${ }^{101}$ were subsequently unable to detect an expected alteration of $\mathrm{Rb}$ phosphorylation status or expression in MPNST, questioning the relevance of prior findings indicating a reduction in p16INK4A. In a separate assessment of 12 MPNSTs, loss of Rb expression was noted in two tumors and LOH was noted in an additional four, half of which were associated with NF1. ${ }^{97}$ Corroborating the data generated by Miller et al., $\mathrm{S} 100 \beta^{147}$ and additionally nestin ${ }^{141}$ have been validated (separately) as diagnostic markers of MPNST. However, other findings implicate non-cell cycle signaling pathways and cellular mechanisms in the process of malignant progression.

Aside from the contribution of specific NF1-associated and cell cycle regulator mutations to malignant progression, components of mitogenic signaling pathways separate from those required for oncogenesis have been implicated, as have elements responsible for immune recognition. The PDGF receptor and fibronectin represent additional proteins that are commonly present in benign neurofibromas but are significantly upregulated in the MPNST. ${ }^{55}$ The authors of multiple studies have concluded that the EGF receptor is also upregulated in MPNST tissue in comparison with normal human Schwann cells. The EGF receptor represents a mitogenic signaling receptor that is upregulated in MPNSTs and is upregulated in at least a subset of cells within benign neurofibromas. ${ }^{28}$ This receptor is homologous to the receptors of the erbB class that are expressed in normal human Schwann cells, are responsive to neuregulins, and have been shown to be constitutively phosphorylated in MPNSTs. Blockade of both receptor types appears to depress the invasive potential of these tumors. Further, a putative link between the EGF receptor and invasive potential has been posited through a link with CD44. Sherman et al. ${ }^{139}$ initially discovered that CD44, a transmembrane protein implicated in cell-cell adhesion, migration, growth factor signaling, and metastasis, is aberrantly overexpressed in MPNSTs but not in benign neurofibromas. This CD44 upregula- 
tion appears to be largely independent of Ras-mediated signaling ${ }^{139}$ and contributes to the invasiveness of the MPNST in a manner at least partially dependent upon the Src-mediated intracellular signaling pathway. ${ }^{145}$ The discovery of an EGF-responsive element in the CD44 promoter provides evidence for the presence of dysregulated EGF-mediated signaling as a contributor to this process. ${ }^{171}$ Further, CD44 upregulation has been linked to enhanced neuregulin-mediated signaling, ${ }^{140}$ indicating a potential for the role of a positive feedback mechanism.

Evasion of immune surveillance has also been implicated in the progression toward malignancy. Data supporting this hypothesis derives from a large-scale profiling of gene expression in an MPNST-derived tumor cell line. Downregulation of immune function-related genes, including genes that produce a transcription factor (MHC2TA), an antigen processing protein (TAPl), and a chaperone protein involved in antigen processing $(C D 74)$, may confer an additional survival advantage to transformed cells that are in the process of malignant invasion. ${ }^{80}$ Together, these data support the conclusion that multiple cell cycle regulators, mitogenic signaling pathways, and evasion of immune surveillance may contribute to the process of malignant progression, yet consistently divergent findings have prevented a unified understanding of the definitive roles of these contributors.

\section{Experimental Therapeutic Strategies}

The current paradigm for the treatment of benign schwannomas and neurofibromas, as well as MPNSTs, centers on resection and extends to the use of adjunctive treatments for postoperative management, including the use of chemo- and radiotherapies. In the context of treating single or isolated lesions, as occurs in the absence of a germline mutation, microsurgical resection may achieve preservation or recovery of neurologic function largely related to relief of compression on eloquent neural structures. In the case of benign tumors, maintenance or improvement of neurological function is most often seen with schwannoma resection. In cases of plexiform neurofibromas, complete tumor resection is often not feasible; instead, tumor debulking and multimodal postoperative management strategies are required. Inability to achieve complete tumor resection poses particular concern in cases of plexiform neurofibroma, given the propensity of these tumors for malignant progression. The high level of invasiveness and metastasis observed in MPNSTs, when coupled with the difficulty of achieving complete resection with microsurgical technique and the suboptimal sensitivity of these tumors to adjunctive treatments, provides the context for current expectations of a poor prognosis. The development of novel therapeutic agents is particularly justified as a means to augment the currently available treatments for NF1-associated lesions. Recent advances in understanding of the molecular mechanisms subserving tumor formation and malignant progression provide the potential for targeted, pathway-specific interventions. In particular, we will discuss currently available off-label therapeutic agents that may yet demonstrate benefit in the treatment of MPNSTs and will broadly distin- guish between agents designed to inhibit or reverse events important to the processes of transformation and progression occurring either in the local microenvironment or specifically at the Schwann cell, focusing on the potential contributions of these agents to future management.

\section{Modification of the Tumor Microenvironment}

The complex microenvironment of the neurofibroma appears to be intricately intertwined with the process of tumor formation, providing multiple parallel opportunities for therapeutic intervention that have the potential to impact both the transformation process and the progression to malignancy, without directly impacting the fundamental dysfunctional processes implicated within the Schwann cell. Specifically, targets within the microenvironment include: mast cells, neoangiogenesis, and tumorrelated fibrosis. In addition to altering the tumor phenotype, modification of the microenvironment holds the potential to generate a milieu that is less permissive to further tumorigenesis or malignant progression.

Mast Cell Inhibition. As discussed previously, the NF1 heterozygote mast cell plays a significant role in the process of neurofibroma-related tumorigenesis, due in part to increased levels of SCF in the local microenvironment, which promote hypermotility, hyperproliferation, and chemotaxis to the tumor microenvironment. In turn, mast cell-mediated signaling is thought to promote further SCF secretion, fibrosis, and angiogenesis through release of its own mediators. To date, the only clinical trials designed directly to inhibit mast cell function used ketotifen fumarate, an antihistamine that helps to stabilize mast cells and prevent degranulation. ${ }^{224,125}$ Patients in the first trial reported subjective improvements in quality of life and decreased pruritus, pain, and tenderness. In terms of effect on tumor size and growth, the results were reported to be consistently positive although less uniform. A second trial corroborated the observed improvement in symptomatology but failed to examine effect on tumor size. ${ }^{124}$

Because the mast cell appears to acquire a pivotal role in coordinating the positive feedback mechanisms of Schwann cell hyperplasia, neovascularization, and fibrosis, therapeutics targeted to the processes of their recruitment and activation hold promise in future attempts at therapeutic intervention. Recruitment to the local neurofibroma microenvironment has been demonstrated to require $\alpha_{4} \beta_{1}$-integrin attachment to the endothelial VCAM-1 receptor. Natalizumab (Tysabri), a monoclonal antibody initially pioneered for its ability to prevent leukocyte migration to demyelinating plaques in patients with multiple sclerosis through inhibition of $\alpha_{4} \beta_{1}$-integrin, was demonstrated to significantly improve outcomes in these patients but was voluntarily withdrawn from studies due to its potential contribution to development of progressive multifocal leukoencephalopathy. However, authors of subsequent studies have concluded that predisposition towards development of progressive multifocal leukoencephalopathy was probably present due to the unique milieu occurring during the pathogenesis of multiple sclerosis and was not directly related to the effects of natalizumab. ${ }^{10}$ In a similar fashion, inhibition of mast cell mi-gration may be expected from downregulation of 
VCAM-1 expression. Tumor necrosis factor- $\alpha$ (TNF $\alpha)$ is known to stimulate VCAM-1 expression, ${ }^{173}$ so use of known inhibitors of TNF $\alpha$, such as the monoclonal antibodies infliximab (Remicade) and etanercept (Enbrel), may merit exploration as therapeutic options. These agents currently represent therapeutic alternatives in chronic inflammatory conditions such as Crohn disease and ulcerative colitis. Since high levels of SCF are thought to play an important role in mast cell activation, either inhibition of SCF or blockade of its receptor, c-kit, also represents a therapeutic alternative. Several potential small molecule and antibody-based inhibitors of SCF and c-kit have been described as potential treatments for allergic inflammation and warrant examination for possible effects on the local microenvironment within the neurofibroma and MPNST. ${ }^{60}$ Imatinib mesylate (Gleevec) was originally designed to exert effect on the bcr-abl signaling pathway, crucial to development of chronic myelogenous leukemia, through interaction with the PDGF receptor. It has since been demonstrated to inhibit c-kit activation and is currently being tested for its therapeutic potential in other malignancies. $^{31}$

Inhibition of Fibrosis. Prevention of mast cell recruitment and activation represent attractive therapeutic endpoints because the mast cell appears to assume both a central and upstream role in the genesis of the tumor microenvironment. Nevertheless, the downstream processes of fibrosis and neovascularization, both observed during tumorigenesis and exacerbated during malignant progression, also represent relevant targets. Pirfenidone, an antifibrotic agent that inhibits fibroblast function by modulating the effect of growth-inducing cytokines, has been tested as a treatment for patients with NF1 and neurofibromas. ${ }^{6}$ In a Phase II study of 24 patients, four patients had a greater than $15 \%$ reduction in tumor volume, the condition of 17 remained unchanged, and three experienced tumor progression to malignancy over a 24-month treatment period (17 patients were treated for the entire period). Volume assessment was performed using 3D magnetic resonance imaging. Other agents-including HMG-CoA reductase inhibitors (statins), ${ }^{157}$ penicillamine, ${ }^{41}$ colchine, ${ }^{35}$ and angiotensin-converting enzyme inhibitors ${ }^{42}$-have been examined for their ability to reduce or reverse collagen deposition in separate in vitro settings. None have yet been systematically examined for their abilities to impact the fibrotic microenvironment in the context of neurofibroma or MPNST treatment. Additionally, interferon- $\gamma$ has been demonstrated to reduce fibroblast activation and proliferation, potentially countering the effects of endogenous mediators such as TGF $\beta .{ }^{11}$ Multiple in vitro experiments by Nakayama et al. have demonstrated the ability of transfected interferon- $\gamma$ to inhibit proliferation of both isolated neurofibroma ${ }^{109,111}$ and MPNST110 cell lines. Further, administration has demonstrated effect in clinical trials of idiopathic pulmonary fibrosis. ${ }^{121}$

Inhibition of Neoangiogenesis. Tumor neovascularization represents a growth requirement beyond an upper diameter of a few millimeters. Studies have corroborated the increased density of vascularity at the microscopic level in the neurofibroma and MPNST, despite the gross pale appearance that is often observed. ${ }^{5}$ To date, thalido- mide represents the only agent that has been examined in the context of a Phase I clinical trial for the treatment of plexiform neurofibromas, specifically for the treatment of neoangiogenesis. ${ }^{47} \mathrm{In}$ an open-label trial involving 20 patients, doses of up to $200 \mathrm{mg}$ /day were tolerated, and the worst adverse event, mild peripheral neuropathy, was transient and occurred in two individuals. Four of the 20 patients noted a reduction in tumor size of less than $25 \%$ as assessed by MR imaging or computed tomography at a 12-month follow-up time point after therapy initiation. Preclinical studies have focused on targeting specific cell types and molecular mediators implicated in the process of neovascularization. The neurofibromin-deficient Schwann cell is the prime contributor to neovascularization, with a shift in the balance of secreted mediators depending upon whether or not both alleles at the NFI locus are intact, ${ }^{66,95}$ but infiltrated mast cells are known to contribute angiogenic mediators such as VEGF. ${ }^{143} \mathrm{We}$ have previously discussed that FGF-2, MK, and PDGF secretion are upregulated in the neurofibromin-deficient Schwann cell. Each of these angiogenic mediators, FGF2, MK, PDGF, and VEGF all have the capability to bind heparin. ${ }^{73}$ Midkine has also been shown to be inhibited by a separate glycosaminoglycan, chondroitin sulfate E. ${ }^{153}$ The potential to achieve direct inhibition of single mediators has been demonstrated in clinical trials of the antiVEGF monoclonal antibody bevacizumab (Avastin) in unrelated conditions. ${ }^{106,132}$ The results of animal model studies, however, have demonstrated that the same result could be achieved using an anti-VEGF immunogen as a vaccine, abolishing concern for generation of a systemic immune reaction that may occur with antibody injections. ${ }^{120}$ Alternatively, gene-based approaches to inhibit VEGF have recently demonstrated promise..$^{71,172}$ One such approach utilized an adenovirus-mediated delivery strategy to simultaneously achieve tumor cell oncolysis and inhibition of VEGF signaling. ${ }^{172}$ Inhibition of individual angiogenic factors may be overcome through alteration in the balance of tumor cell receptor expression and possibly through the use of alternate signaling pathways. Therefore, the use of a single agent that simultaneously blocks multiple mediators holds increased promise in achieving reduced neovascularization. However, direct inhibition of the aforementioned angiogenic mediators by heparin alone has not demonstrated efficacy. In an animal model in which human nerve sheath tumors are removed from patients and implanted into the subrenal capsule of female athymic mice (nu/nu), the tumors were histologically indistinguishable from human tumors. ${ }^{73}$ Using this animal model, the researchers found that treatment with heparin alone resulted in an increase in tumor vascularity that correlated with an increase in tumor size. Use of hydrocortisone alone failed to achieve an effect. Yet, coadministration of heparin and hydrocortisone resulted in simultaneous decreases in neovascularization and tumor size. ${ }^{77}$ This dependence of effect on hormone status has been corroborated in breast cancer studies. Simultaneous administration of heparin with tamoxifen, a partial estrogen antagonist, achieved a more demonstrable effect than either alone. ${ }^{99}$ Alternative strategies for inhibition of neovascularization include inhibition of individual angiogenic receptors and direct prevention of proliferation.

A variety of inhibitors have been investigated in the 
attempt to attenuate receptor activation. The most biologically relevant VEGF receptor appears to be VEGFR-2. The VEGFR-2 inhibitors that have been assessed include neutralizing antibodies, ${ }^{126}$ ribozymes directed to this receptor, ${ }^{116}$ antisense strategies, ${ }^{133}$ and small molecule inhibitors. ${ }^{3,151}$ Additionally, strategies have been attempted to directly inhibit endothelial cell proliferation. Treatment with proliferation inhibitors, such as TNP-470, has been shown to decrease tumor vascularity and size more than treatment with placebo in the athymic mouse model, described earlier in this section. ${ }^{73}$ Finally, the process of neovascularization encompasses its own microenvironment, with signaling between pericytes and endothelial cells playing an important role in angiogenic sprouting and tube formation. ${ }^{15}$ Multiple studies have shown that inhibition of pericytes may also serve as a means to limit neovascularization, in the treatment of both neurofibromas and MNPSTs as well as other malignancies. ${ }^{113,114}$

\section{Schwann Cell-Specific Approaches}

While strategies aimed at the tumor microenvironment largely focus on slowing invasiveness or growth potential or disrupting the self-perpetuating trophic support feedback cycle, therapeutics targeted to the Schwann cell represent a more direct approach by which to halt or reverse the causative mechanisms underlying initiation and maintenance of processes responsible for transformation and malignant progression. However, the majority of Schwann cell-specific therapeutic approaches operate by manipulating cell-surface receptors specialized for transduction of mitogenic signals or by modulating the function of contributory intracellular signaling pathways. The targeting of EGF and PDGF receptors represent the predominant strategies for inhibiting transmembrane signaling receptors. Conversely, strategies designed to disrupt intracellular signaling pathways interact with Ras production, components of the Ras pathway, or downstream effectors.

Directed Therapeutics for Cell-Surface Mitogen Receptors. Upregulation of physiologically relevant transmembrane cell surface receptors associated with intracellular mitogen signaling cascades is a common finding in tumors that have undergone clinical progression to malignancy. Specifically, evidence to indicate upregulation of the EGF and PDGF receptors has been previously cited. Because both are receptor tyrosine kinases that act as first steps within various Ras-mediated signaling cascades, their blockade represents an attractive therapeutic target. Preclinical studies have demonstrated that blockade of the EGF receptor-related erbB receptors with PD168393 and PD158780 have blocked proliferation of MPNST cells in an in vitro setting. ${ }^{144}$ The utility of direct EGF receptor blockade with gefitinib (Iressa) as a potential therapeutic end point for MPNST treatment has also been demonstrated in an in vitro setting. ${ }^{30}$ In addition to having been demonstrated in preclinical and clinical studies for the treatment of a wide variety of cancers, ${ }^{34}$ EGF receptor blockade has been extended into the clinical context for treatment of MPNSTs. In a recently published abstract, Albritton et al. ${ }^{2}$ examined erlotinib as a therapeutic approach for treatment of unresectable or metastatic MPNSTs. Of 24 enrolled patients, 20 were deemed eligible for treatment. At a median survival of 4 months, no demonstrable effect on progression was noted, and one patient was noted to have stable disease. Accrual of patients into the trial was halted because of the lack of objective evidence of treatment effect. Although a clinical trial for treatment of MPNST through PDGF receptor inhibition has not been reported, this receptor has been identified as a potential contributor to tumor progression and so represents a potential therapeutic target. ${ }^{24}$

Directed Therapeutics for Intracellular Signaling Pathways. The Ras protein undergoes posttranslational modification with the ultimate result of achieving membrane attachment. $^{30}$ The cysteine residue closest to the carboxyterminus is joined with a 15-lipid moiety, a farnesyl group. Following prenylation, the three remaining residues are cleaved, and carboxymethylation occurs at the same cysteine residue. Following the addition of the farnesyl lipid moiety, the Ras protein undergoes addition of separate lipid moieties, either achieving palmitoylation in the H-Ras or N-Ras isoforms or addition of a poly-Llysine (polybasic) motif in the K-Ras4B isoform. This results in targeting to separate cell membrane microdomains and in the use of distinct intracellular recycling pathways. ${ }^{119}$ Further, each isoform is known to preferentially interact with subsets of known downstream effectors. $\mathrm{H}$-Ras appears to preferentially activate PI3K, whereas $\mathrm{K}-\mathrm{Ras} 4 \mathrm{~B}$ interacts more readily with Raf and Rac. ${ }^{166}$ Although the fundamental roles of the distinct lipid moieties present on different Ras isoforms have yet to be fully discerned, therapeutic strategies designed to broadly manipulate Ras prenylation have been explored under the assumption that inappropriate subcellular localization will negatively impact Ras-mediated signaling.

Ras Prenylation Inhibitors. The 15-carbon farnesyl group attached to the carboxyl cysteine is generated through the biosynthetic pathway responsible for cholesterol formation. The rate-limiting enzyme within this biochemical cascade, HMG-CoA reductase, is inhibited by the statin family of pharmacological agents. Because the cholesterol biosynthetic pathway is also important for the production of multiple lipid- and cholesterol-based derivatives required for cell growth and mitogenesis, statins have been demonstrated to negatively impact multiple aspects of tumorigenesis. Preclinical data have indicated that simvastatin can reverse the malignant progression of a fibroblast cell line following constitutive expression of a Ras oncogene. ${ }^{40}$ Further, an effect of simvistatin has been noted in a variety of cancers associated with increased Ras-mediated signaling. ${ }^{15,21,64}$ Although the current literature does not specifically examine the potential utility of statins for the treatment of benign or malignant peripheral nerve tumors, lovastatin has been demonstrated to reduce cognitive impairment and to inhibit Ras-mediated signaling in a mouse model of NF1. ${ }^{82}$ The broad intracellular effects of cholesterol and lipid moieties indicates that statins probably have a much broader role in inhibiting tumor formation or malignant progression than through Ras alone. ${ }^{29,38,84}$

Targeting of farneysl transferase represents the second major method whereby the inhibition of prenylation has been approached. Farnesyl transferase inhibitors prevent attachment of the 15-carbon lipid moiety to the Ras carboxyterminus. Because dysregulation of Ras signaling occurs in multiple cancers, FTIs have been explored in 
preclinical and clinical contexts as treatment strategies for multiple benign and malignant tumors, including those of Schwann cell origin. Evidence has suggested utility in a variety of xenograft cancer models, including models of hematological, head and neck, ovarian, lung, colon, breast, bladder, and prostate cancer and melanoma. $4,9,30$ Findings related to nerve sheath tumors include the demonstration that FTIs have the capability to significantly reduce hyperproliferation and clone formation in NF1deficient mice that demonstrated significantly increased proliferation after administration of forskolin, an activator of adenylate cyclase. Subsequent treatment with an FTI (L-739749) significantly reduced hyperproliferation but not invasiveness, leading the authors to postulate the potential utility of FTIs for benign nerve sheath tumors. ${ }^{66}$ Prior to the publication of these findings, Yan et al. ${ }^{167}$ had demonstrated that treatment of an MPNST-derived cell line, ST88-14, resulted in loss of many phenotypic characteristics of malignancy, with the cell line becoming contact-inhibited, flat, and non-refractile and losing the capability to grow in soft agar. Further, treated cells were incapable of associating Ras to the inner leaflet of the cell membrane. A Phase I clinical trial assessing FTI (tipifarnib) monotherapy has recently been completed. Pediatric patients 2 to 18 years of age, with either solid tumors or NF1-related plexiform neurofibromas, were treated with tipifarnib. Average farnesyl transferase activity was reduced to $44 \%$ (median 35\%) of baseline in a manner that could not be correlated with the assessed dosing regimens. ${ }^{159}$ Although the study generated dose-ranging safety data that have served as the basis for a subsequent Phase II trial (National Cancer Institute protocol ID NCT00021541), lack of observed response, including in the patients with plexiform neurofibromas, is in line with the results observed in use of FTIs in clinical trials for other cancers. ${ }^{53,123,129} \mathrm{~A}$ potential reason for the poor clinical results obtained with FTI monotherapy may be related to the inability of FTIs to block membrane association of the K-Ras or N-Ras isoforms - that is, the limitation of their blocking to the association of H-Ras. The K- and $\mathrm{N}$-Ras isoforms are capable of undergoing geranylgeranylation when farnesyl transferase is inactivated, a compensatory reaction that functionally substitutes for farnesylation. Further, Mattingly et al. have demonstrated that $\mathrm{K}$ - and N-Ras isoforms represent the predominant isoforms observed in human NF1 cell lines. ${ }^{30,96}$ Alternative strategies to prevent Ras prenylation are under investigation, including inhibition of geranylgeranyl transferase, ${ }^{118}$ Ras converting enzyme, and carboxymethylase. ${ }^{30}$ Much as with the attempts to use statins to prevent biosynthesis of lipid moieties, inhibition of prenylation can be expected to exert a wide range of intracellular effects, as it represents a broad cellular strategy for membrane anchorage.

Direct Ras Inhibition Strategies. Several techniques, including Ras prenylation, have been designed to modulate the dysregulation of intracellular pathways observed in peripheral nerve tumors. One such alternative approach designed to directly achieve Ras inhibition has been accomplished through use of farnesylthiosalicylic acid, an agent that inhibits all Ras isoforms by competing with Ras-GTP for saturable binding sites in the cell membrane. ${ }^{7}$ The same authors demonstrated reversal of the transformed phenotype and tumor growth inhibition in multiple MPNST cell lines, including ST88-14, S265P21, and 90-8.7 Alternatively, reconstitution of the neurofibromin GRD has demonstrated promise in multiple preclinical contexts. Hiatt et $\mathrm{al}^{54}$ achieved normalization of growth and Ras-Erk signaling in transformed $\mathrm{NF}^{-1-}$ mouse fibroblast and hematopoietic cells. Most recently, Thomas et al ${ }^{149}$ have demonstrated that stable retroviral delivery of the GRD to human $\mathrm{NFI}^{-/-}$Schwann cells is capable of reducing Ras activation by 16 to $33 \%$ and the proliferation of the cells by $53 \%$. Nevertheless, in vitro angiogenic potential was not inhibited, indicating only partial reversal of the transformed phenotype. Expression of either the NF1 gene or the GRD-related region of this gene in a colorectal cancer cell line with oncogenic K-Ras was capable of suppressing tumor formation in vitro. ${ }^{83}$ The neurofibromin GRD reduces the ability of the NIH 3T3 $N F 1$-deficient fibroblast and hematopoietic cell lines to form colonies in an in vitro environment. ${ }^{54}$ Further, depression of K-Ras and N-Ras activity, in association with inhibited proliferation of acute myeloid leukemia cells has been demonstrated through expression of the neurofibromin GRD in cells deficient for this protein. ${ }^{102}$ Preclinical studies have also examined modulation of related and downstream signaling effector pathways.

Targeting Signal Transduction Pathways. Merlin was previously discussed as playing a tumor suppressor role through prevention of Rac activation. Activated through Ras-dependent and -independent mechanisms, Rac plays a central role in further activation of the Ras pathway through Pak-mediated phosphorylation of downstream Ras effectors. Both overexpression of merlin and provision of dominant negative Pak have been examined as strategies to reverse the transformation process, at least partially through modulation of elevated Ras-mediated signaling. Merlin overexpression has been demonstrated to reverse transformation in an NIH 3T3 fibroblast cell line transfected with an oncogenic variant of Ras. ${ }^{150} \mathrm{Ad}-$ ditional studies have indicated effects extending to downstream effector pathways. ${ }^{65,85}$ Dominant negative Pak mutants, delivered by stable retroviral transduction, have been demonstrated to potently inhibit the transformation process in both rat Schwann cells and in an MPNST cell line derived from a patient with NF1. ${ }^{148}$ In alternative approaches, investigators have explored direct inhibition of downstream signal transduction pathways. Mattingly et al. ${ }^{96}$ have recently demonstrated the antiproliferative effects of multiple Erk1/2 MAPK inhibitors PD98059, PD184352, and U0126, in three MPNST cell lines. Both PD98059 and PD184352 demonstrated cytoxicity when applied to tumor cells, whereas U0126 demonstrated a cytostatic result. Only PD184352 significantly reduced Erk1/2 MAPK activation, but it simultaneously promoted apoptosis in a control rat Schwann cell line, suggesting that demyelinating peripheral neuropathy could limit its therapeutic potential. Separate in vitro ${ }^{108}$ and in vivo ${ }^{86}$ studies of varied cancers have examined Erk inhibition with sorafenib, a multikinase inhibitor; the results have demonstrated the capacity to inhibit angiogenesis, to reduce cellular proliferation, and induce apoptosis. The wide range of effects was thought to be due to the promiscuity of sorafenib, as it is known to inhibit the function of 
multiple receptor tyrosine kinases, in addition to inhibiting Erk.

Inhibition of PI3K/Akt-mediated signaling has been attempted through reduction of substrate for PI3K and through the use of agents that act at both PI3K and at Akt. A tumor suppressor gene mutated in several cancers, $P T E N$, is responsible for breakdown of phosphatidylinositol $(3,4,5)$-triphosphate, an activator of Akt and the enzymatic product of the interaction of phosphatidylinositol (4,5)-bisphosphate and PI3K. Adenoviral-mediated overexpression of PTEN has been employed in both in vitro and in vivo studies for the treatment of bladder ${ }^{164}$ and colorectal cancer. ${ }^{131}$ Classic research-oriented inhibitors of PI3K include wortmannin and LY294002. The former covalently binds the catalytic subunit of PI3K, and the latter competes with ATP for the ATP binding site. ${ }^{17}$ Not only has LY294002 been shown to reduce in vitro MPNST cell growth following EGF receptor stimulation, ${ }^{81}$ it has also been shown to have the capability to sensitize a variety of tumor cell types (for example, prostate adenocarcinoma, renal adenocarcinoma, bladder carcino$\mathrm{ma}$, and colon carcinoma cells) to apoptosis in the presence of a microtubule destabilizing agent. ${ }^{39}$ The clinical usefulness of both LY294002 and wortmannin has, however, been limited by their solubility and stability. ${ }^{17} \mathrm{~A}$ rationally derived wortmannin derivative, PWT-458, has been reported to potently inhibit PI3K in xenograft tumors (for example, gliomas, non-small cell lung cancers, and renal cell carcinomas) grown in nude mice with better therapeutic index than wortmannin. ${ }^{170} \mathrm{~A}$ separate compound, PX-866, has been demonstrated to have broadspectrum PI3K inhibitory capacity and has demonstrated antitumor capacity in severe combined immunodeficiency mouse model studies, increasing the effects of both cisplatin and radiation. ${ }^{57}$ Also known as protein kinase B, Akt has 53\% homology with protein kinase C and 47\% homology with protein kinase A, which places a premium on the use of rational drug design to generate an Akt-specific agent. Generation of structure-based inhibitors has produced Akt-selective agents that are pharmacokinetically and pharmacodynamically stable ${ }^{14}$ but recognition that the three known Akt isoforms may play distinct roles in oncogenesis has prompted an acknowledgment that isoform-specific agents may be required. ${ }^{33}$ Finally, the absence of functional neurofibromin has been implicated as a cause for constitutive activation of tuberin and mTOR, both downstream effectors of PI3K/Akt, as described previously. ${ }^{62}$ Rapamycin and related agents have been demonstrated to significantly inhibit signaling through this pathway. ${ }^{23,62}$ Downstream inhibition of the numerous conserved molecular effectors of these pathways controlling cellular growth, proliferation, survival, and apoptosis has been explored because these agents are valuable both as research tools and as potential cancer therapies for a broad range of conditions.

Schwann Cell-Specific Oncolytic Approaches. Schwann cell-specific oncolysis represents a unique therapeutic paradigm in the spectrum of peripheral nerve tumor treatment strategies. Delivery of a viral vector as an anticancer agent has been hypothesized to achieve effect through direct oncolysis, induction of antitumoral immunity, and chemo- or radiosensitization. ${ }^{69}$ The ability to achieve viral tropism for tumor cells represents a novel approach to specifically target rapidly dividing tumor cells while sparing the surrounding quiescent parenchyma. Such tropism was initially thought to result from an alteration of interferon-mediated antiviral responses stemming from dysregulated Ras-mediated signaling. However, evidence for uptake into MPNST cell lines that either did or did not display dysregulated Ras signaling but not into normal human Schwann cells has provided the rationale for an alternate mechanism. ${ }^{92}$ This observation suggests that attenuated but still replication-competent viruses (oncolytic viruses) can be used to selectively kill tumor cells. Additional data now indicate a role for elevated PI3K-mediated signaling in oncolytic HSV tumor cell tropism. Broadly based strategies using this therapeutic approach to prevent clinical infection with are achieved by deletion of multiple viral genes required for replication in quiescent cells. Therefore, attenuated viral vectors become capable of replicating only in those cells that can supplement the action of the deleted genes. Because the enzymatic machinery of cell division is upregulated in rapidly dividing tumor cells, viral replication and oncolysis are constrained to this cell population. Deleted genes may include ribonucleotide reductase, a virulence factor (ICP34.5) important for protein translation, and multiple latency-associated genes. ${ }^{92}$ After initial demonstration that MPNST cells are permissive for multiple oncolytic HSV variants and undergo selective oncolysis as compared with normal human Schwann cells, Messerli et al. ${ }^{100}$ have demonstrated the antitumor effectiveness of an oncolytic HSV-based treatment in both xenograft transplant and dominant mutant NF2 mouse models. Mahller and colleagues ${ }^{93}$ have subsequently extended their previous results to the use of combination therapy by coadministration of oncolytic HSV with the angiogenesis inhibitor erlotinib. ${ }^{93}$ When the agents were administered individually, the oncolytic HSV was noted to have significant antitumor effects, whereas erlotinib-treated animals developed a trend toward tumor reduction. Although overall cell killing was higher in the animals that received both agents, an additive antiMPNST effect was not noted. Simultaneous treatment with erlotinib did not inhibit the replicative or tumor cell killing capacity of the oncolytic HSV. Subsequent studies have examined incorporation of specific transgenes designed to augment the oncolytic HSV-mediated tumor cell killing capacity. Liu et al. ${ }^{87}$ have demonstrated that incorporation of the dominant-negative FGF receptor into an oncolytic HSV resulted in improved killing of both MPNST cells and endothelial cells as compared with the effect of oncolytic HSV alone or transfection with dominant-negative FGF receptor alone, when studied in vitro. The oncolytic HSV with dominant-negative FGF receptor demonstrated greater in vivo inhibition of angiogenesis and tumor growth than did an oncolytic HSV vector without the dominant-negative FGF receptor. A similar result was attained when Liu et al. ${ }^{88}$ used a separate transgene, platelet factor 4 , specifically chosen for its known antiangiogenic effects. It is likely that subsequent research will explore mechanisms to improve viral tumor distribution and to place ICP34.5 under a tumor-specific promoter as well as to explore additional potential anti-tumor transgenes. ${ }^{93}$ 


\section{Conclusions and Future Directions}

Current surgical therapy is largely effective for isolated neurofibromas and schwannomas. Near-term surgical advances will probably involve incorporation of minimally invasive methods of impeding tumor progression, which would permit the treatment of a larger number of suspicious lesions. Such a technique could also be applied to the difficult challenge of treating large plexiform neurofibromas in otherwise functional nerves. The current level of morbidity associated with resection together with the diffuse nature of NF1-related tumors prevents the elimination of risk for malignant transformation, indicating a need for therapeutic strategies capable of directly addressing the underlying mechanisms responsible for peripheral nerve tumor transformation and malignant progression. In the preceding text, recent progress in elucidation of the pathways of peripheral nerve tumorigenesis and malignant peripheral nerve tumor progression has been outlined. Recognition of the causative roles played by neurofibromin and merlin at the NF1 and NF2 loci has served a crucial role in further developing an understanding of the molecular pathogenesis of neurofibromas, schwannomas, and MPNSTs. Although intensive research is still required to fully unravel the putative initiation and progression mechanisms, the current level of understanding provides the framework necessary for the development of rational therapeutic agents designed to inhibit known contributors to both the initiation and progression pathways. Potential therapeutic avenues are varied, impacting both pathways directly related to the known causative mutation as well as elements of the surrounding microenvironment. It will be of significant importance, in the near future, to press forward in the attempt to target disparate components of the known and putative molecular pathways due in part to the potential for redundancy within implicated intracellular and extracellular signaling pathways. This is supported by the findings of current literature for treatment of other malignancies in which Ras-mediated dysregulation is thought to play a central role, where efforts to target individual components alone have yet to generate a curative approach. ${ }^{103}$ Therefore, near-term future therapies attempted with curative intent will probably still require multimodal therapeutic intervention.

\section{References}

1. Akhmametyeva EM, Mihaylova MM, Luo H, Kharzai S, Welling DB, Chang LS: Regulation of the neurofibromatosis 2 gene promoter expression during embryonic development. Dev Dyn 235:2771-2785, 2006

2. Albritton Kea: Phase II study of erlotinib in metastatic or unresectable malignant peripheral nerve sheath tumors (MPNST). J Clin Oncol 24 (18 Suppl): (Abstract)2006

3. Angelov L, Salhia B, Roncari L, McMahon G, Guha A: Inhibition of angiogenesis by blocking activation of the vascular endothelial growth factor receptor 2 leads to decreased growth of neurogenic sarcomas. Cancer Res 59:5536-5541, 1999

4. Appels NM, Beijnen JH, Schellens JH: Development of farnesyl transferase inhibitors: a review. Oncologist 10:565-578, 2005

5. Arbiser JL, Flynn E, Barnhill RL: Analysis of vascularity of human neurofibromas. J Am Acad Dermatol 38:950-954, 1998
6. Babovic-Vuksanovic D, Ballman K, Michels V, McGrann P, Lindor N, King B, et al: Phase II trial of pirfenidone in adults with neurofibromatosis type 1 . Neurology 67:1860-1862, 2006

7. Barkan B, Starinsky S, Friedman E, Stein R, Kloog Y: The Ras inhibitor farnesylthiosalicylic acid as a potential therapy for neurofibromatosis type 1. Clin Cancer Res 12:5533-5542, 2006

8. Bashour AM, Meng JJ, Ip W, MacCollin M, Ratner N: The neurofibromatosis type 2 gene product, merlin, reverses the F-actin cytoskeletal defects in primary human Schwannoma cells. Mol Cell Biol 22:1150-1157, 2002

9. Basso AD, Kirschmeier P, Bishop WR: Lipid posttranslational modifications. Farnesyl transferase inhibitors. J Lipid Res 47: 15-31, 2006

10. Bennett JL: Natalizumab and progressive multifocal leukoencephalopathy: migrating towards safe adhesion molecule therapy in multiple sclerosis. Neurol Res 28:291-298, 2006

11. Bhatt N, Baran CP, Allen J, Magro C, Marsh CB: Promising pharmacologic innovations in treating pulmonary fibrosis. Curr Opin Pharmacol 6:284-292, 2006

12. Birindelli S, Perrone F, Oggionni M, Lavarino C, Pasini B, Vergani B, et al: Rb and TP53 pathway alterations in sporadic and NF1-related malignant peripheral nerve sheath tumors. Lab Invest 81:833-844, 2001

13. Brannan CI, Perkins AS, Vogel KS, Ratner N, Nordlund ML, Reid SW, et al: Targeted disruption of the neurofibromatosis type-1 gene leads to developmental abnormalities in heart and various neural crest-derived tissues. Genes Dev 8:1019-1029, 1994

14. Breitenlechner CB, Friebe WG, Brunet E, Werner G, Graul K, Thomas U, et al: Design and crystal structures of protein kinase B-selective inhibitors in complex with protein kinase A and mutants. J Med Chem 48:163-170, 2005

15. Campbell MJ, Esserman LJ, Zhou Y, Shoemaker M, Lobo M, Borman E, et al: Breast cancer growth prevention by statins. Cancer Res 66:8707-8714, 2006

16. Cawthon RM, O'Connell P, Buchberg AM, Viskochil D, Weiss $\mathrm{RB}, \mathrm{Culver} \mathrm{M}$, et al: Identification and characterization of transcripts from the neurofibromatosis 1 region: the sequence and genomic structure of EVI2 and mapping of other transcripts. Genomics 7:555-565, 1990

17. Chen YL, Law PY, Loh HH: Inhibition of PI3K/Akt signaling: an emerging paradigm for targeted cancer therapy. Curr Med Chem Anticancer Agents 5:575-589, 2005

18. Chen Z, Fadiel A, Xia Y: Functional duality of merlin: A conundrum of proteome complexity. Med Hypotheses 67: 1095-1098, 2006

19. Cichowski K, Santiago S, Jardim M, Johnson BW, Jacks T: Dynamic regulation of the Ras pathway via proteolysis of the NF1 tumor suppressor. Genes Dev 17:449-454, 2003

20. Cichowski K, Shih TS, Schmitt E, Santiago S, Reilly K, McLaughlin ME, et al: Mouse models of tumor development in neurofibromatosis type 1. Science 286:2172-2176, 1999

21. Clutterbuck RD, Millar BC, Powles RL, Newman A, Catovsky D, Jarman M, et al: Inhibitory effect of simvastatin on the proliferation of human myeloid leukaemia cells in severe combined immunodeficient (SCID) mice. Br J Haematol 102: 522-527, 1998

22. Coles LC, Shaw PE: PAK1 primes MEK1 for phosphorylation by Raf-1 kinase during cross-cascade activation of the ERK pathway. Oncogene 21:2236-2244, 2002

23. Dancey JE: Therapeutic targets: MTOR and related pathways. Cancer Biol Ther 5:1065-1073, 2006

24. Dang I, DeVries GH: Schwann cell lines derived from malignant peripheral nerve sheath tumors respond abnormally to platelet-derived growth factor-BB. J Neurosci Res 79: 318-328, 2005

25. Dasgupta B, Yi Y, Chen DY, Weber JD, Gutmann DH: Pro- 
teomic analysis reveals hyperactivation of the mammalian target of rapamycin pathway in neurofibromatosis 1-associated human and mouse brain tumors. Cancer Res 65:2755-2760, 2005

26. De Raedt T, Brems H, Wolkenstein P, Vidaud D, Pilotti S, Perrone F, et al: Elevated risk for MPNST in NF1 microdeletion patients. Am J Hum Genet 72:1288-1292, 2003

27. DeClue JE, Cohen BD, Lowy DR: Identification and characterization of the neurofibromatosis type 1 protein product. Proc Natl Acad Sci U S A 88:9914-9918, 1991

28. DeClue JE, Heffelfinger S, Benvenuto G, Ling B, Li S, Rui W, et al: Epidermal growth factor receptor expression in neurofibromatosis type 1-related tumors and NF1 animal models. J Clin Invest 105:1233-1241, 2000

29. DeClue JE, Vass WC, Papageorge AG, Lowy DR, Willumsen BM: Inhibition of cell growth by lovastatin is independent of ras function. Cancer Res 51:712-717, 1991

30. Dilworth JT, Kraniak JM, Wojtkowiak JW, Gibbs RA, Borch RF, Tainsky MA, et al: Molecular targets for emerging antitumor therapies for neurofibromatosis type 1. Biochem Pharmacol 72:1485-1492, 2006

31. Druker BJ: Perspectives on the development of a molecularly targeted agent. Cancer Cell 1:31-36, 2002

32. Ducatman BS, Scheithauer BW, Piepgras DG, Reiman HM, Ilstrup DM: Malignant peripheral nerve sheath tumors. A clinicopathologic study of 120 cases. Cancer 57:2006-2021, 1986

33. Dummler B, Hemmings BA: Physiological roles of PKB/Akt isoforms in development and disease. Biochem Soc Trans 35:231-235, 2007

34. Dutta PR, Maity A: Cellular responses to EGFR inhibitors and their relevance to cancer therapy. Cancer Lett epub ahead of print, 2007

35. Entzian P, Schlaak M, Seitzer U, Bufe A, Acil Y, Zabel P: Antiinflammatory and antifibrotic properties of colchicine: implications for idiopathic pulmonary fibrosis. Lung 175:41-51, 1997

36. Evans DG, Baser ME, McGaughran J, Sharif S, Howard E, Moran A: Malignant peripheral nerve sheath tumors in neurofibromatosis 1. J Med Genet 39:311-314, 2002

37. Ferner RE, Gutmann DH: International consensus statement on malignant peripheral nerve sheath tumors in neurofibromatosis. Cancer Res 62:1573-1577, 2002

38. Fritz G: HMG-CoA reductase inhibitors (statins) as anticancer drugs (review). Int J Oncol 27:1401-1409, 2005

39. Fujiwara Y, Hosokawa Y, Watanabe K, Tanimura S, Ozaki K, Kohno M: Blockade of the phosphatidylinositol-3-kinase-Akt signaling pathway enhances the induction of apoptosis by microtubule-destabilizing agents in tumor cells in which the pathway is constitutively activated. Mol Cancer Ther 6: 1133-1142, 2007

40. Furst J, Haller T, Chwatal S, Woll E, Dartsch PC, Gschwentner $M$, et al: Simvastatin inhibits malignant transformation following expression of the Ha-ras oncogene in NIH $3 \mathrm{~T} 3$ fibroblasts. Cell Physiol Biochem 12:19-30, 2002

41. Geismar LS, Hennessey S, Reiser KM, Last JA: D-penicillamine prevents collagen accumulation in lungs of rats given bleomycin. Chest 89 (3 Suppl):153S-154S, 1986

42. Ghazi-Khansari M, Mohammadi-Karakani A, Sotoudeh M, Mokhtary P, Pour-Esmaeil E, Maghsoud S: Antifibrotic effect of captopril and enalapril on paraquat-induced lung fibrosis in rats. J Appl Toxicol: (epub ahead of print, 2007)

43. Giovannini M, Robanus-Maandag E, Niwa-Kawakita M, van der Valk M, Woodruff JM, Goutebroze L, et al: Schwann cell hyperplasia and tumors in transgenic mice expressing a naturally occurring mutant NF2 protein. Genes Dev 13:978-986, 1999

44. Gonzalez-Gomez P, Bello MJ, Alonso ME, Lomas J, Arjona D, Campos JM, et al: CpG island methylation in sporadic and neurofibromatis type 2-associated schwannomas. Clin Cancer Res 9:5601-5606, 2003
45. Gottfried ON, Viskochil DH, Fults DW, Couldwell WT: Molecular, genetic, and cellular pathogenesis of neurofibromas and surgical implications. Neurosurgery 58:1-16, 2006

46. Gregory PE, Gutmann DH, Mitchell A, Park S, Boguski M, Jacks T, et al: Neurofibromatosis type 1 gene product (neurofibromin) associates with microtubules. Somat Cell Mol Genet 19:265-274, 1993

47. Gupta A, Cohen BH, Ruggieri P, Packer RJ, Phillips PC: Phase I study of thalidomide for the treatment of plexiform neurofibroma in neurofibromatosis 1. Neurology 60:130-132, 2003

48. Gutmann DH, Cole JL, Collins FS: Expression of the neurofibromatosis type 1 (NF1) gene during mouse embryonic development. Prog Brain Res 105:327-335, 1995

49. Gutmann DH, Geist RT, Wright DE, Snider WD: Expression of the neurofibromatosis 1 (NF1) isoforms in developing and adult rat tissues. Cell Growth Differ 6:315-323, 1995

50. Gutmann DH, Wright DE, Geist RT, Snider WD: Expression of the neurofibromatosis 2 (NF2) gene isoforms during rat embryonic development. Hum Mol Genet 4:471-478, 1995

51. Hamaratoglu F, Willecke M, Kango-Singh M, Nolo R, Hyun E, Tao C, et al: The tumor-suppressor genes NF2/Merlin and Expanded act through Hippo signalling to regulate cell proliferation and apoptosis. Nat Cell Biol 8:27-36, 2006

52. Heim RA, Silverman LM, Farber RA, Kam-Morgan LN, Luce MC: Screening for truncated NF1 proteins. Nat Genet 8: 218-219, 1994

53. Heymach JV, Johnson DH, Khuri FR, Safran H, Schlabach LL, Yunus F, et al: Phase II study of the farnesyl transferase inhibitor R115777 in patients with sensitive relapse small-cell lung cancer. Ann Oncol 15:1187-1193, 2004

54. Hiatt KK, Ingram DA, Zhang Y, Bollag G, Clapp DW: Neurofibromin GTPase-activating protein-related domains restore normal growth in Nf1-/-cells. J Biol Chem 276: 7240-7245, 2001

55. Holtkamp N, Mautner VF, Friedrich RE, Harder A, Hartmann C, Theallier-Janko A, et al: Differentially expressed genes in neurofibromatosis 1-associated neurofibromas and malignant peripheral nerve sheath tumors. Acta Neuropathol 107: 159-168, 2004

56. Huang JH, Zhang J, Zager EL: Diagnosis and treatment options for nerve sheath tumors. Expert Rev Neurother 5:515-523, 2005

57. Ihle NT, Williams R, Chow S, Chew W, Berggren MI, PaineMurrieta G, et al: Molecular pharmacology and antitumor activity of PX-866, a novel inhibitor of phosphoinositide-3-kinase signaling. Mol Cancer Ther 3:763-772, 2004

58. Jacks T, Shih TS, Schmitt EM, Bronson RT, Bernards A, Weinberg RA: Tumour predisposition in mice heterozygous for a targeted mutation in Nf1. Nat Genet 7:353-361, 1994

59. Janowski M: ras proteins and the ras-related signal transduction pathway. Radiat Environ Biophys 30:185-189, 1991

60. Jensen BM, Metcalfe DD, Gilfillan AM: Targeting kit activation: a potential therapeutic approach in the treatment of allergic inflammation. Inflamm Allergy Drug Targets 6:57-62, 2007

61. Jin H, Sperka T, Herrlich P, Morrison H: Tumorigenic transformation by CPI-17 through inhibition of a merlin phosphatase. Nature 442:576-579, 2006

62. Johannessen CM, Reczek EE, James MF, Brems H, Legius E, Cichowski K: The NF1 tumor suppressor critically regulates TSC2 and mTOR. Proc Natl Acad Sci U S A 102:8573-8578, 2005

63. Jung JR, Kim H, Jeun SS, Lee JY, Koh EJ, Ji C: The phosphorylation status of merlin is important for regulating the RasERK pathway. Mol Cells 20:196-200, 2005

64. Khanzada UK, Pardo OE, Meier C, Downward J, Seckl MJ, Arcaro A: Potent inhibition of small-cell lung cancer cell growth by simvastatin reveals selective functions of Ras isoforms in growth factor signalling. Oncogene 25:877-887, 2006 
65. Kim H, Lim JY, Kim YH, Kim H, Park SH, Lee KH, et al: Inhibition of ras-mediated activator protein 1 activity and cell growth by merlin. Mol Cells 14:108-114, 2002

66. Kim HA, Ling B, Ratner N: Nf1-deficient mouse Schwann cells are angiogenic and invasive and can be induced to hyperproliferate: reversion of some phenotypes by an inhibitor of farnesyl protein transferase. Mol Cell Biol 17:862-872, 1997

67. Kindblom LG, Ahlden M, Meis-Kindblom JM, Stenman G: Immunohistochemical and molecular analysis of p53, MDM2, proliferating cell nuclear antigen and Ki67 in benign and malignant peripheral nerve sheath tumors. Virchows Arch 427: 19-26, 1995

68. Kino T, Takeshima H, Nakao M, Nishi T, Yamamoto K, Kimura $\mathrm{T}$, et al: Identification of the cis-acting region in the NF2 gene promoter as a potential target for mutation and methylation-dependent silencing in schwannoma. Genes Cells 6: 441-454, 2001

69. Kirn D, Martuza RL, Zwiebel J: Replication-selective virotherapy for cancer: biological principles, risk management and future directions. Nat Med 7:781-787, 2001

70. Kluwe L, Friedrich RE, Mautner VF: Allelic loss of the NF1 gene in NF1-associated plexiform neurofibromas. Cancer Genet Cytogenet 113:65-69, 1999

71. Kommareddy S, Amiji M: Antiangiogenic gene therapy with systemically administered sFlt-1 plasmid DNA in engineered gelatin-based nanovectors. Cancer Gene Ther 14:488-498, 2007

72. Kourea HP, Bilsky MH, Leung DH, Lewis JJ, Woodruff JM: Subdiaphragmatic and intrathoracic paraspinal malignant peripheral nerve sheath tumors: a clinicopathologic study of 25 patients and 26 tumors. Cancer 82:2191-2203, 1998

73. Kurtz A, Martuza RL: Antiangiogenesis in neurofibromatosis 1. J Child Neurol 17:578-584; discussion 602-574, 646-651, 2002

74. Lallemand D, Curto M, Saotome I, Giovannini M, McClatchey AI: NF2 deficiency promotes tumorigenesis and metastasis by destabilizing adherens junctions. Genes Dev 17:1090-1100, 2003

75. Le LQ, Parada LF: Tumor microenvironment and neurofibromatosis type I: connecting the GAPs. Oncogene epub ahead of print, 2007

76. Lee H, Kim D, Dan HC, Wu EL, Gritsko TM, Cao C, et al: Identification and characterization of putative tumor suppressor NGB, a GTP-binding protein that interacts with the neurofibromatosis 2 protein. Mol Cell Biol 27:2103-2119, 2007

77. Lee JK, Choi B, Sobel RA, Chiocca EA, Martuza RL: Inhibition of growth and angiogenesis of human neurofibrosarcoma by heparin and hydrocortisone. J Neurosurg 73: 429-435, 1990

78. Lee JY, Kim H, Ryu CH, Kim JY, Choi BH, Lim Y, et al: Merlin, a tumor suppressor, interacts with transactivationresponsive RNA-binding protein and inhibits its oncogenic activity. J Biol Chem 279:30265-30273, 2004

79. Lee JY, Moon HJ, Lee WK, Chun HJ, Han CW, Jeon YW, et al: Merlin facilitates ubiquitination and degradation of transactivation-responsive RNA-binding protein. Oncogene 25: $1143-1152,2006$

80. Lee PR, Cohen JE, Fields RD: Immune system evasion by peripheral nerve sheath tumor. Neurosci Lett 397:126-129, 2006

81. Li H, Velasco-Miguel S, Vass WC, Parada LF, DeClue JE: Epidermal growth factor receptor signaling pathways are associated with tumorigenesis in the Nf1:p53 mouse tumor model. Cancer Res 62:4507-4513, 2002

82. Li W, Cui Y, Kushner SA, Brown RA, Jentsch JD, Frankland PW, et al: The HMG-CoA reductase inhibitor lovastatin reverses the learning and attention deficits in a mouse model of neurofibromatosis type 1. Curr Biol 15:1961-1967, 2005

83. Li Y, White R: Suppression of a human colon cancer cell line by introduction of an exogenous NF1 gene. Cancer Res 56: 2872-2876, 1996

84. Li YC, Park MJ, Ye SK, Kim CW, Kim YN: Elevated levels of cholesterol-rich lipid rafts in cancer cells are correlated with apoptosis sensitivity induced by cholesterol-depleting agents. Am J Pathol 168:1107-1118; quiz 1404-1405, 2006

85. Lim JY, Kim H, Kim YH, Kim SW, Huh PW, Lee KH, et al: Merlin suppresses the SRE-dependent transcription by inhibiting the activation of Ras-ERK pathway. Biochem Biophys Res Commun 302:238-245, 2003

86. Liu L, Cao Y, Chen C, Zhang X, McNabola A, Wilkie D, et al: Sorafenib blocks the RAF/MEK/ERK pathway, inhibits tumor angiogenesis, and induces tumor cell apoptosis in hepatocellular carcinoma model PLC/PRF/5. Cancer Res 66: 11851-11858, 2006

87. Liu TC, Zhang T, Fukuhara H, Kuroda T, Todo T, Canron X, et al: Dominant-negative fibroblast growth factor receptor expression enhances antitumoral potency of oncolytic herpes simplex virus in neural tumors. Clin Cancer Res 12: 6791-6799, 2006

88. Liu TC, Zhang T, Fukuhara H, Kuroda T, Todo T, Martuza RL, et al: Oncolytic HSV armed with platelet factor 4, an antiangiogenic agent, shows enhanced efficacy. Mol Ther 14: 789-797, 2006

89. Lothe RA, Smith-Sorensen B, Hektoen M, Stenwig AE, Mandahl N, Saeter G, et al: Biallelic inactivation of TP53 rarely contributes to the development of malignant peripheral nerve sheath tumors. Genes Chromosomes Cancer 30:202-206, 2001

90. Lutchman M, Rouleau GA: The neurofibromatosis type 2 gene product, schwannomin, suppresses growth of NIH 3T3 cells. Cancer Res 55:2270-2274, 1995

91. Maeda M, Matsui T, Imamura M, Tsukita S, Tsukita S: Expression level, subcellular distribution and rho-GDI binding affinity of merlin in comparison with Ezrin/Radixin/Moesin proteins. Oncogene 18:4788-4797, 1999

92. Mahller YY, Rangwala F, Ratner N, Cripe TP: Malignant peripheral nerve sheath tumors with high and low Ras-GTP are permissive for oncolytic herpes simplex virus mutants. Pediatr Blood Cancer 46:745-754, 2006

93. Mahller YY, Vaikunth SS, Currier MA, Miller SJ, Ripberger MC, Hsu YH, et al: Oncolytic HSV and erlotinib inhibit tumor growth and angiogenesis in a novel malignant peripheral nerve sheath tumor xenograft model. Mol Ther 15:279-286, 2007

94. Maitra S, Kulikauskas RM, Gavilan H, Fehon RG: The tumor suppressors Merlin and Expanded function cooperatively to modulate receptor endocytosis and signaling. Curr Biol 16:702-709, 2006

95. Mashour GA, Ratner N, Khan GA, Wang HL, Martuza RL, Kurtz A: The angiogenic factor midkine is aberrantly expressed in NF1-deficient Schwann cells and is a mitogen for neurofibroma-derived cells. Oncogene 20:97-105, 2001

96. Mattingly RR, Kraniak JM, Dilworth JT, Mathieu P, Bealmear $\mathrm{B}$, Nowak JE, et al: The mitogen-activated protein kinase/extracellular signal-regulated kinase kinase inhibitor PD184352 (CI1040) selectively induces apoptosis in malignant schwannoma cell lines. J Pharmacol Exp Ther 316:456-465, 2006

97. Mawrin C, Kirches E, Boltze C, Dietzmann K, Roessner A, Schneider-Stock R: Immunohistochemical and molecular analysis of $\mathrm{p} 53, \mathrm{RB}$, and PTEN in malignant peripheral nerve sheath tumors. Virchows Arch 440:610-615, 2002

98. McClatchey AI, Saotome I, Ramesh V, Gusella JF, Jacks T: The Nf2 tumor suppressor gene product is essential for extraembryonic development immediately prior to gastrulation. Genes Dev 11:1253-1265, 1997

99. McLeskey SW, Zhang L, Trock BJ, Kharbanda S, Liu Y, Gottardis MM, et al: Effects of AGM-1470 and pentosan polysulphate on tumorigenicity and metastasis of FGF-transfected MCF-7 cells. Br J Cancer 73:1053-1062, 1996 
100. Messerli SM, Prabhakar S, Tang Y, Mahmood U, Giovannini $\mathrm{M}$, Weissleder R, et al: Treatment of schwannomas with an oncolytic recombinant herpes simplex virus in murine models of neurofibromatosis type 2. Hum Gene Ther 17:20-30, 2006

101. Miller SJ, Rangwala F, Williams J, Ackerman P, Kong S, Jegga AG, et al: Large-scale molecular comparison of human schwann cells to malignant peripheral nerve sheath tumor cell lines and tissues. Cancer Res 66:2584-2591, 2006

102. Morgan KJ, Rowley MA, Wiesner SM, Hasz DE, Van Ness B, Largaespada DA: The GAP-related domain of neurofibromin attenuates proliferation and downregulates $\mathrm{N}$-and K-Ras activation in Nf1-negative AML cells. Leuk Res, epub ahead of print, 2007

103. Morgan MA, Ganser A, Reuter CW: Targeting the RAS signaling pathway in malignant hematologic diseases. Curr Drug Targets 8:217-235, 2007

104. Morrison H, Sherman LS, Legg J, Banine F, Isacke C, Haipek CA, et al: The NF2 tumor suppressor gene product, merlin, mediates contact inhibition of growth through interactions with CD44. Genes Dev 15:968-980, 2001

105. Morrison H, Sperka T, Manent J, Giovannini M, Ponta H, Herrlich P: Merlin/neurofibromatosis type 2 suppresses growth by inhibiting the activation of Ras and Rac. Cancer Res 67:520-527, 2007

106. Moshfeghi AA, Rosenfeld PJ, Puliafito CA, Michels S, Marcus EN, Lenchus JD, et al: Systemic bevacizumab (Avastin) therapy for neovascular age-related macular degeneration: twentyfour-week results of an uncontrolled open-label clinical study. Ophthalmology 113:2002.e1-2002.e12, 2006

107. Munchhof AM, Li F, White HA, Mead LE, Krier TR, Fenoglio A, et al: Neurofibroma-associated growth factors activate a distinct signaling network to alter the function of neurofibromin-deficient endothelial cells. Hum Mol Genet 15: 1858-1869, 2006

108. Murphy DA, Makonnen S, Lassoued W, Feldman MD, Carter C, Lee WM: Inhibition of tumor endothelial ERK activation, angiogenesis, and tumor growth by sorafenib (BAY43-9006). Am J Pathol 169:1875-1885, 2006

109. Nakayama J, Tanaka T, Arakawa F, Terao H, Shimura H, Ikeda $\mathrm{S}$, et al: Gamma interferon gene transfection efficiently inhibits proliferation of neurofibroma cell lines in vitro. J Dermatol 30:181-188, 2003

110. Nakayama J, Tanaka T, Furumura M, Takahashi A, Yamaguchi $\mathrm{T}$, Shimura H, et al: Inhibition of the proliferation of a malignant peripheral nerve sheath tumor cell line by gamma interferon gene transfection. J Dermatol 30:879-885, 2003

111. Nakayama J, Terao H: Gamma interferon directly inhibits the growth of neurofibroma cells in vitro. J Dermatol 29: 556-561, 2002

112. O'Connell P, Cawthon R, Xu GF, Li Y, Viskochil D, White R: The neurofibromatosis type 1 (NF1) gene: identification and partial characterization of a putative tumor suppressor gene. $\mathbf{J}$ Dermatol 19:881-884, 1992

113. Ozerdem U: Targeting neovascular pericytes in neurofibromatosis type 1. Angiogenesis 7:307-311, 2004

114. Ozerdem U: Targeting of pericytes diminishes neovascularization and lymphangiogenesis in prostate cancer. Prostate 66:294-304, 2006

115. Ozerdem U, Stallcup WB: Early contribution of pericytes to angiogenic sprouting and tube formation. Angiogenesis 6: 241-249, 2003

116. Pavco PA, Bouhana KS, Gallegos AM, Agrawal A, Blanchard KS, Grimm SL, et al: Antitumor and antimetastatic activity of ribozymes targeting the messenger RNA of vascular endothelial growth factor receptors. Clin Cancer Res 6:2094-2103, 2000

117. Pelton PD, Sherman LS, Rizvi TA, Marchionni MA, Wood P, Friedman RA, et al: Ruffling membrane, stress fiber, cell spreading and proliferation abnormalities in human Schwannoma cells. Oncogene 17:2195-2209, 1998

118. Peterson YK, Kelly P, Weinbaum CA, Casey PJ: A novel protein geranylgeranyltransferase-I inhibitor with high potency, selectivity, and cellular activity. J Biol Chem 281: 12445-12450, 2006

119. Prior IA, Muncke C, Parton RG, Hancock JF: Direct visualization of Ras proteins in spatially distinct cell surface microdomains. J Cell Biol 160:165-170, 2003

120. Rad FH, Le Buanec H, Paturance S, Larcier P, Genne P, Ryffel $\mathrm{B}$, et al: VEGF kinoid vaccine, a therapeutic approach against tumor angiogenesis and metastases. Proc Natl Acad Sci U S A 104:2837-2842, 2007

121. Raghu G, Brown KK, Bradford WZ, Starko K, Noble PW, Schwartz DA, et al: A placebo-controlled trial of interferon gamma-1b in patients with idiopathic pulmonary fibrosis. $\mathbf{N}$ Engl J Med 350:125-133, 2004

122. Ramesh V: Merlin and the ERM proteins in Schwann cells, neurons and growth cones. Nat Rev Neurosci 5:462-470, 2004

123. Rao S, Cunningham D, de Gramont A, Scheithauer W, Smakal M, Humblet Y, et al: Phase III double-blind placebo-controlled study of farnesyl transferase inhibitor R115777 in patients with refractory advanced colorectal cancer. J Clin Oncol 22:3950-3957, 2004

124. Riccardi VM: A controlled multiphase trial of ketotifen to minimize neurofibroma-associated pain and itching. Arch Dermatol 129:577-581, 1993

125. Riccardi VM: Mast-cell stabilization to decrease neurofibroma growth. Preliminary experience with ketotifen. Arch Dermatol 123:1011-1016, 1987

126. Rockwell PN, Neufeld G, Classman, A, Caron, D, Goldstein, $\mathrm{N}$ : In vitro neutralization of vascular endothelial growth factor activation of Flk-1 by monoclonal antibody. Mol Cell Differ 3:91-109, 1995

127. Rong R, Surace EI, Haipek CA, Gutmann DH, Ye K: Serine 518 phosphorylation modulates merlin intramolecular association and binding to critical effectors important for NF2 growth suppression. Oncogene 23:8447-8454, 2004

128. Rong R, Tang X, Gutmann DH, Ye K: Neurofibromatosis 2 (NF2) tumor suppressor merlin inhibits phosphatidylinositol 3-kinase through binding to PIKE-L. Proc Natl Acad Sci U S A 101:18200-18205, 2004

129. Rosenberg JE, von der Maase H, Seigne JD, Mardiak J, Vaughn DJ, Moore M, et al: A phase II trial of R115777, an oral farnesyl transferase inhibitor, in patients with advanced urothelial tract transitional cell carcinoma. Cancer 103: 2035-2041, 2005

130. Ryu CH, Kim SW, Lee KH, Lee JY, Kim H, Lee WK, et al: The merlin tumor suppressor interacts with Ral guanine nucleotide dissociation stimulator and inhibits its activity. Oncogene 24:5355-5364, 2005

131. Saito Y, Swanson X, Mhashilkar AM, Oida Y, Schrock R, Branch CD, et al: Adenovirus-mediated transfer of the PTEN gene inhibits human colorectal cancer growth in vitro and in vivo. Gene Ther 10:1961-1969, 2003

132. Sakaguchi H, Ikuno Y, Gomi F, Kamei M, Sawa M, Tsujikawa $\mathrm{M}$, et al: Intravitreal injection of bevacizumab for choroidal neovascularisation associated with pathological myopia. Br J Ophthalmol 91:161-165, 2007

133. Saleh M, Stacker SA, Wilks AF: Inhibition of growth of C6 glioma cells in vivo by expression of antisense vascular endothelial growth factor sequence. Cancer Res 56:393-401, 1996

134. Sanguinetti C, Greco F, de Palma L, Specchia N, Toesca A, Nori S: The ultrastructure of schwannoma and neurofibroma of the peripheral nerves. Ital J Orthop Traumatol 17: 237-246, 1991

135. Schulze KM, Hanemann CO, Muller HW, Hanenberg H: Transduction of wild-type merlin into human schwannoma 
cells decreases schwannoma cell growth and induces apoptosis. Hum Mol Genet 11:69-76, 2002

136. Scoles DR, Huynh DP, Morcos PA, Coulsell ER, Robinson NG, Tamanoi F, et al: Neurofibromatosis 2 tumor suppressor schwannomin interacts with betaII-spectrin. Nat Genet 18: 354-359, 1998

137. Shaw RJ, Paez JG, Curto M, Yaktine A, Pruitt WM, Saotome I, et al: The Nf2 tumor suppressor, merlin, functions in Racdependent signaling. Dev Cell 1:63-72, 2001

138. Shen MH, Harper PS, Upadhyaya M: Molecular genetics of neurofibromatosis type 1 (NF1). J Med Genet 33:2-17, 1996

139. Sherman L, Jacoby LB, Lampe J, Pelton P, Aguzzi A, Herrlich $\mathrm{P}$, et al: CD44 expression is aberrant in benign Schwann cell tumors possessing mutations in the neurofibromatosis type 2, but not type 1, gene. Cancer Res 57:4889-4897, 1997

140. Sherman LS, Rizvi TA, Karyala S, Ratner N: CD44 enhances neuregulin signaling by Schwann cells. J Cell Biol 150: 1071-1084, 2000

141. Shimada S, Tsuzuki T, Kuroda M, Nagasaka T, Hara K, Takahashi E, et al: Nestin expression as a new marker in malignant peripheral nerve sheath tumors. Pathol Int 57:60-67, 2007

142. Skovronsky DM, Oberholtzer JC: Pathologic classification of peripheral nerve tumors. Neurosurg Clin N Am 15:157-166, 2004

143. Sondell M, Lundborg G, Kanje M: Vascular endothelial growth factor has neurotrophic activity and stimulates axonal outgrowth, enhancing cell survival and Schwann cell proliferation in the peripheral nervous system. J Neurosci 19:5731-5740, 1999

144. Stonecypher MS, Byer SJ, Grizzle WE, Carroll SL: Activation of the neuregulin-1/ErbB signaling pathway promotes the proliferation of neoplastic Schwann cells in human malignant peripheral nerve sheath tumors. Oncogene 24:5589-5605, 2005

145. Su W, Sin M, Darrow A, Sherman LS: Malignant peripheral nerve sheath tumor cell invasion is facilitated by Src and aberrant CD44 expression. Glia 42:350-358, 2003

146. Sun CX, Robb VA, Gutmann DH: Protein 4.1 tumor suppressors: getting a FERM grip on growth regulation. J Cell Sci 115:3991-4000, 2002

147. Takeuchi A, Ushigome S: Diverse differentiation in malignant peripheral nerve sheath tumors associated with neurofibromatosis-1: an immunohistochemical and ultrastructural study. Histopathology 39:298-309, 2001

148. Tang Y, Marwaha S, Rutkowski JL, Tennekoon GI, Phillips PC, Field J: A role for Pak protein kinases in Schwann cell transformation. Proc Natl Acad Sci U S A 95:5139-5144, 1998

149. Thomas SL, Deadwyler GD, Tang J, Stubbs EB Jr, Muir D, Hiatt KK, et al: Reconstitution of the NF1 GAP-related domain in NF1-deficient human Schwann cells. Biochem Biophys Res Commun 348:971-980, 2006

150. Tikoo A, Varga M, Ramesh V, Gusella J, Maruta H: An antiRas function of neurofibromatosis type 2 gene product (NF2/Merlin). J Biol Chem 269:23387-23390, 1994

151. Tille JC, Wood J, Mandriota SJ, Schnell C, Ferrari S, Mestan $\mathrm{J}$, et al: Vascular endothelial growth factor (VEGF) receptor-2 antagonists inhibit VEGF-and basic fibroblast growth factorinduced angiogenesis in vivo and in vitro. J Pharmacol Exp Ther 299: 1073-1085, 2001

152. Trovo-Marqui AB, Tajara EH: Neurofibromin: a general outlook. Clin Genet 70:1-13, 2006

153. Ueoka C, Kaneda N, Okazaki I, Nadanaka S, Muramatsu T, Sugahara K: Neuronal cell adhesion, mediated by the heparinbinding neuroregulatory factor midkine, is specifically inhibited by chondroitin sulfate E. Structural ans functional implications of the over-sulfated chondroitin sulfate. J Biol Chem 275:37407-37413, 2000
154. Upadhyaya M, Spurlock G, Majounie E, Griffiths S, Forrester $\mathrm{N}$, Baser M, et al: The heterogeneous nature of germline mutations in NF1 patients with malignant peripheral serve sheath tumors (MPNSTs). Hum Mutat 27:716, 2006

155. Vogel KS, Klesse LJ, Velasco-Miguel S, Meyers K, Rushing EJ, Parada LF: Mouse tumor model for neurofibromatosis type 1. Science 286:2176-2179, 1999

156. von Deimling AF, Krone W: Familial Tumor Syndromes Involving the Nervous System, in Pathology and Genetic Tumors of the Nervous System. Lyon, IARC Press, 2000, pp 216-218

157. Watts KL, Sampson EM, Schultz GS, Spiteri MA: Simvastatin inhibits growth factor expression and modulates profibrogenic markers in lung fibroblasts. Am J Respir Cell Mol Biol 32: 290-300, 2005

158. Weiss B, Bollag G, Shannon K: Hyperactive Ras as a therapeutic target in neurofibromatosis type 1. Am J Med Genet 89:14-22, 1999

159. Widemann BC, Salzer WL, Arceci RJ, Blaney SM, Fox E, End D, et al: Phase I trial and pharmacokinetic study of the farnesyltransferase inhibitor tipifarnib in children with refractory solid tumors or neurofibromatosis type I and plexiform neurofibromas. J Clin Oncol 24:507-516, 2006

160. Wong WW, Hirose T, Scheithauer BW, Schild SE, Gunderson LL: Malignant peripheral nerve sheath tumor: analysis of treatment outcome. Int J Radiat Oncol Biol Phys 42: 351-360, 1998

161. Woodruff JM, Selig AM, Crowley K, Allen PW: Schwannoma (neurilemoma) with malignant transformation. A rare, distinctive peripheral nerve tumor. Am J Surg Pathol 18:882-895, 1994

162. Woods R, Friedman JM, Evans DG, Baser ME, Joe H: Exploring the "two-hit hypothesis" in NF2: tests of two-hit and three-hit models of vestibular schwannoma development. Genet Epidemiol 24:265-272, 2003

163. Wu M, Wallace MR, Muir D: Nf1 haploinsufficiency augments angiogenesis. Oncogene 25:2297-2303, 2006

164. Wu ZX, Song TB, Li DM, Zhang XT, Wu XL: Overexpression of PTEN suppresses growth and induces apoptosis by inhibiting the expression of survivin in bladder cancer cells. Tumour Biol 28:9-15, 2007

165. Xiao GH, Gallagher R, Shetler J, Skele K, Altomare DA, Pestell RG, et al: The NF2 tumor suppressor gene product, merlin, inhibits cell proliferation and cell cycle progression by repressing cyclin D1 expression. Mol Cell Biol 25: 2384-2394, 2005

166. Yan J, Roy S, Apolloni A, Lane A, Hancock JF: Ras isoforms vary in their ability to activate Raf-1 and phosphoinositide 3kinase. J Biol Chem 273:24052-24056, 1998

167. Yan N, Ricca C, Fletcher J, Glover T, Seizinger BR, Manne V: Farnesyltransferase inhibitors block the neurofibromatosis type I (NF1) malignant phenotype. Cancer Res 55: 3569-3575, 1995

168. Yang FC, Chen S, Clegg T, Li X, Morgan T, Estwick SA, et al: $\mathrm{Nf} 1+/$-mast cells induce neurofibroma like phenotypes through secreted TGF-beta signaling. Hum Mol Genet 15: 2421-2437, 2006

169. Yang FC, Ingram DA, Chen S, Hingtgen CM, Ratner N, Monk KR, et al: Neurofibromin-deficient Schwann cells secrete a potent migratory stimulus for Nf1+/-mast cells. J Clin Invest 112:1851-1861, 2003

170. Yu K, Lucas J, Zhu T, Zask A, Gaydos C, Toral-Barza L, et al: PWT-458, a novel pegylated-17-hydroxywortmannin, inhibits phosphatidylinositol 3-kinase signaling and suppresses growth of solid tumors. Cancer Biol Ther 4:538-545, 2005

171. Zhang M, Wang MH, Singh RK, Wells A, Siegal GP: Epidermal growth factor induces CD44 gene expression through a novel regulatory element in mouse fibroblasts. J Biol Chem 272:14139-14146, 1997 
172. Zhang Z, Zou W, Wang J, Gu J, Dang Y, Li B, et al: Suppression of tumor growth by oncolytic adenovirus-mediated delivery of an antiangiogenic gene, soluble Flt-1. Mol Ther 11:553-562, 2005

173. Zhou Z, Connell MC, Macewan DJ: TNFR1-induced NFkappaB, but not ERK, p38MAPK or JNK activation, mediates TNF-induced ICAM-1 and VCAM-1 expression on endothelial cells. Cell Signal 19:1238-1248, 2007

174. Zhu Y, Ghosh P, Charnay P, Burns DK, Parada LF: Neurofibromas in NF1: Schwann cell origin and role of tumor environment. Science 296:920-922, 2002
175. Zhu Y, Parada LF: The molecular and genetic basis of neurological tumors. Nat Rev Cancer 2:616-626, 2002

Manuscript submitted April 23, 2007.

Accepted April 30, 2007.

Address reprint requests to: Nicholas M. Boulis, M.D., Cleveland Clinic_-Lerner Research Institute NB2-126, Department of Neurosciences and Center for Neurological Restoration, 9500 Euclid Avenue, Cleveland, Ohio 44195. email: boulisn@ccf.org. 